\title{
Momentum and Contrarian Profits and Macroeconomic Fundamentals
}

\author{
Ming Liu \\ The Chinese University of Hong Kong \\ Harold H. Zhang \\ University of Texas at Dallas \\ Xinting Fan \\ The Chinese University of Hong Kong
}

This Version: March 2008

\begin{abstract}
Xinting Fan and Ming Liu are from the Chinese University of Hong Kong. Harold H. Zhang is from the School of Management at the University of Texas at Dallas. Please address correspondence to Harold H. Zhang, School of Management, University of Texas at Dallas, Box 830688, SM 31, Richardson, TX 75083. email:harold.zhang@utdallas.edu, Tel: (972) 883 4777. Any errors are our own.
\end{abstract}




\title{
Momentum and Contrarian Profits and Macroeconomic Fundamentals
}

\begin{abstract}
We show that the existence of momentum and contrarian profits imposes restrictions on stochastic discount factors used to price stocks in equity markets. For several widely used asset pricing models, we demonstrate that these restrictions imply testable forms of intertemporal dependence in macroeconomic fundamentals such as consumption growth rate. Extensive empirical analysis provides supporting evidence that the momentum and contrarian profits manifest the short-term continuation and the longterm reversal in the macroeconomic fundamentals. Intuitively, the dynamics of the macroeconomic fundamentals induces a common return persistence for individual stocks. When coupled with the selection of past winners and losers, the return persistence generates the momentum and contrarian profits.
\end{abstract}

Keywords: Momentum and contrarian profits, Return persistence, Macroeconomic fundamentals 


\section{Introduction}

In this paper we show that the existence of momentum and contrarian profits imposes restrictions on the stochastic discount factor (SDF) used to price stocks in equity markets. For various asset pricing models, we demonstrate that these restrictions imply specific testable forms of intertemporal dependence in macroeconomic fundamentals such as the consumption growth rate. Extensive empirical tests on these intertemporal dependence restrictions lend strong support on the relation between momentum and contrarian profits and macroeconomic fundamentals. Our analysis suggests that the momentum and contrarian profits manifest the short-term continuation and the long-term reversal in macroeconomic fundamentals. Intuitively, the dynamics of macroeconomic fundamentals induces an intertemporal dependence in the stochastic discount factor. When used to price stocks in equity markets, the stochastic discount factor generates a co-movement component of returns across different stocks. This co-movement component, coupled with the selection of past winners and losers to form the momentum and contrarian portfolios, generates the widely documented trading profits for these strategies. ${ }^{1}$

Several recent empirical studies found evidence supporting the existence of a relation between the momentum and contrarian profits and macroeconomic activities. For instance, Chordia and Shivakumar (2002) document that a collection of past macroeconomic variables predict momentum returns, whereas Liu, Warner, Zhang (2005) show that winner stocks and loser stocks load differently on the common factor of the industrial production growth rate. Using a dynamic principal component analysis, Jiang and Yao (2006) also document that momentum profits are due to stock return response to a small number of dynamic systematic factors. ${ }^{2}$ To the extent that the contrarian profit is related to the value premium (Fama and French (1996)), recent literature (Lettau and

\footnotetext{
1 With a momentum strategy, a portfolio of stocks that outperformed the market over the previous 3 to 12 months (winners) is bought and a portfolio of stocks that underperformed in the market over the same period (losers) is sold. The winner-minus-loser portfolio is then held for the next 3 to 12 months. In contrast, with a contrarian strategy a portfolio of stocks that underperformed the market over the previous 24 to 60 months (losers) is bought and a portfolio of stocks that outperformed the market over the same period is sold. An incomplete list of studies on the momentum profit includes Lewellen (2002), Jegadeesh and Titman (2001, 2002), Grundy and Martin (2001), Chordia and Shivakumar (2002), Griffin, Ji, and Martin (2003), Cooper, Gutierrez, and Hameed (2004), George and Hwang (2004), Korajczyk and Sadka (2004), among others. For discussions on the contrarian profit, see the references in Conrad and Kaul (1998) for details.

${ }^{2}$ While they point to a possible link to observed economic factors, their study does not explicitly establish
} 
Ludvigson (2001) and Bansal and Yaron (2004), among others) also implies that the contrarian profit is attributable to the time-varying macroeconomic risks.

While the empirical evidence suggests a possible relation between momentum and contrarian profits and macroeconomic variables, existing studies do not explicitly identify the macroeconomic foundation of these trading strategies. By directly examining the restrictions of the momentum and contrarian profits on the stochastic discount factors, we are able to establish the structural economic relation between momentum and contrarian profits and macroeconomic fundamentals. Our study complements existing studies which document the statistical relation between momentum and contrarian profits and macroeconomic variables.

We begin with a careful examination of the return persistence for the crosssection of stocks and its relation to momentum and contrarian profits. As pointed out by Cochrane (2001, page 447), "momentum is really a new way of looking at an old phenomenon, the small apparent predictability of monthly individual stock returns. A tiny regression $R^{2}$ for forecasting monthly return of $0.0025(1 / 4 \%)$ is more than adequate to generate the momentum results ... The key is the large standard deviation of individual stock returns, typically $40 \%$ or more at an annual basis. ... so the winning momentum portfolio typically went up about $80 \%$ in the previous year, and the typical losing portfolio went down about $60 \%$ per year. Only a small amount of continuation will give a $1 \%$ monthly return when multiplied by such large past returns." The key issue is the source of the weak stock return continuation or persistence. We attribute the stock return continuation (or reversal) to the dynamics of macroeconomic fundamentals. In particular, we explicitly derive and empirically test the structural economic relation between the momentum and contrarian profits and macroeconomic fundamentals for several widely used asset pricing models.

Following this direction, we model the return persistence for the cross-section of individual stocks as the time-varying slope coefficient of regressing the cross-section of stock returns in the holding period (portfolios held) on the cross-section of stock returns in the formation period (portfolios formed), i.e.,

$$
r_{i, t+h}=a_{t+h}+b_{t+h} r_{i, t-f}+\varepsilon_{i, t+h},
$$

where $r_{i, t+h}$ and $r_{i, t-f}$ are individual stock returns in the holding and formation periods, 
respectively, $a_{t+h}$ and $b_{t+h}$ are time-varying coefficients that are identical across individual stocks, and $\varepsilon_{i, t+h}$ is the error term. The slope coefficient, $b_{t+h}$, measures the common level of return persistence from time $t-f$ to time $t+h$ and captures the co-movement of stock returns relative to the previous cross-section of stock returns.

Under the no-arbitrage principle, the return persistence imposes restrictions on the intertemporal dependence of the stochastic discount factor. Because stochastic discount factors are in general a function of macroeconomic fundamentals, we can further establish the relation between the return persistence and the dynamics of macroeconomic fundamentals utilizing the restrictions on the stochastic discount factor. For three widely investigated asset pricing models including (1) the standard Lucas (1978) constant relative risk aversion (CRRA) preference model, (2) the Epstein and Zin (1989) recursive preference model, and (3) the Campbell and Cochrane (1999) external habit formation model, we derive explicit testable restrictions on the relation between the return persistence of individual stocks and the macroeconomic fundamentals such as the consumption growth rate or the surplus consumption growth rate. ${ }^{3}$

In our empirical analysis, we first estimate the return persistence parameters and demonstrate that the return persistence coupled with the selection of past winner and loser portfolios accounts for the observed momentum and contrarian profits in the data. We then use the generalized method of moments (GMM) to empirically investigate the relation between the return persistence and the dynamics of macroeconomic fundamentals by testing the restrictions on the consumption growth rate or surplus consumption growth rate derived under specific asset pricing models. Finally, we perform robustness checks using alternative regression analysis on the intertemporal dependence restrictions.

Our empirical analysis provides the following findings. First, by selecting the top $10 \%$ stocks to form the winner portfolio and the bottom $10 \%$ stocks to form the loser portfolio based on the return performance in the formation period, we show that the common return persistence coupled with the selection mechanism explains around $90 \%$ of the time-series variation in both momentum and contrarian profits. Controlling for this interaction, the "abnormal" momentum and contrarian returns in the period after 1947 are

\footnotetext{
${ }^{3}$ Consumption growth rate is widely considered to be close to serially independent. However, Hamilton (1989) and Cecchetti, Lam and Mark (1990), among many others, find that consumption growth rate dynamics contains a persistent but small predictable component.
} 
reduced to $0.2 \%$ and $0.3 \%$ per annum, respectively.

Further, the existence of the return persistence allows us to decompose the return to the market portfolio into a persistence-related component and a non-persistence related component. ${ }^{4}$ Previous studies have documented that total market returns exhibit no or a slightly negative short-term autocorrelation (for example, Lewellen (2002)), and conclude that the momentum profit is unlikely to be caused by broad market economic risk. Our market return decomposition demonstrates that it is the persistence-related component that exhibits the short-term return continuation. The negative autocorrelation in the market return is likely caused by the reversal of the non-persistence related component, which may outweigh the continuation of the persistence component. Our market return decomposition thus offers an explanation for the co-existence of a negative serial autocorrelation in market returns and the momentum profit caused by broad market risks.

Second, our empirical tests indicate a strong relation between momentum and contrarian profits and the macroeconomic fundamentals such as the consumption growth rate or the surplus consumption growth rate. Momentum and contrarian profits manifest the short-term continuation and the long-term reversal of these macroeconomic fundamentals. Specifically, our GMM conditional tests using the $J$-statistic show that the restrictions on the stochastic discount factor cannot be rejected for any of the three asset pricing models. The p-value for the over-identification test ranges from $60 \%$ for the external-habit formation model, to $63 \%$ for the CRRA model, to $90 \%$ for the Epstein-Zin model when we force the models to match both the momentum and contrarian profits. Further, the estimated risk aversion coefficient or curvature parameter ranges from 2.9 for the Epstein-Zin model to 5.5 for the external-habit model to 6.2 for the CRRA model. For the Epstein-Zin recursive preferences, the estimated elasticity of intertemporal substitution (EIS) remains very low at 0.08 . This is consistent with the finding reported in Kandel and Stambaugh (1991). The estimated persistence parameter for the external habit is 0.84 and in line with the calibrated parameter value used in Campbell and Cochrane (1999).

In a prior study, Kandel and Stambaugh (1991) find it difficult for the Epstein-Zin model to generate the short-term continuation in stock index return using annual

\footnotetext{
${ }^{4}$ Although we conduct the empirical analysis on both the equally and value weighted market portfolio indexes, the results reported in the paper mainly refer to the equally weighted market index portfolio.
} 
consumption growth rate process to generate return persistence. This is attributed to the lack of short-term continuation in annual consumption growth rate. In contrast, our investigation uses quarterly consumption growth rate, which exhibits a much stronger short-term continuation, and is able to generate the return persistence for cross section of stock returns.

Our study offers an alternative perspective on the debate regarding the sources of momentum profit. For instance, Jegadeesh and Titman (1993) and Grundy and Martin (2001) argue that momentum profit mainly results from the persistence in the returns of extreme winners and losers. Johnson (2002) proposes a single firm model with persistent dividend growth rate shocks in some states of the economy and show that momentum effects are consistent with rational behavior. He interprets the persistent growth rate shocks as representing major changes in business conditions. However, he does not take his analysis to the multiform level nor does he consider general equilibrium effects.

In contrast, Lewellen (2002) documents that well diversified portfolios of stocks also are capable of producing significant momentum profit. He attributes momentum profit to the excess covariance among the cross-section of returns. We show that such an excess covariance can be characterized by a simple form of return co-movement: the common return persistence across the broad market that is related to the dynamics of macroeconomic fundamentals.

A large number of behavioral models are also proposed as possible explanations, such as the initial underreaction caused by "conservatism bias" as detailed by Barberis, Shleifer and Vishny (1998), the "overconfidence bias" that is posited by Daniel, Hirshleifer and Subrahmanyam (1998), the "asymmetric response delay" of Hong and Stein (1999), and the "spread convergence" between fundamental value and reference price of Grinblatt and Han (2005), among others. Our study suggests that momentum and contrarian profits emerge in response to the short-term continuation and the long-term reversal in macroeconomic fundamentals. To the extent that these behavioral models offer explanations for the dynamics of the macroeconomic fundamentals, our findings also accommodate the behavioral explanations to be the possible source of momentum and contrarian profits.

The remainder of the paper is organized as follows. In Section 2 we establish the relation between the return persistence and macroeconomic fundamentals using the stochastic discount factors. In particular, we derive explicit testable restrictions on the 
macroeconomic fundamentals for three widely investigated asset pricing models. Section 3 discusses empirical analysis results. Section 4 provides concluding remarks. Proofs are given in the Appendix.

\section{Momentum and Contrarian Profits and Macroeconomic Fundamentals}

We establish the structural economic relation between the momentum and contrarian profits and macroeconomic fundamentals in two steps. First, we propose a specification for the return persistence for the cross-section of stocks and relate the momentum and contrarian profits to the return persistence and the selection of winner and loser portfolios based on stock returns in formation period. The specified return persistence captures the co-movement of the entire market for all stocks. Second, we explore the restrictions on the stochastic discount factor imposed by the return persistence. For three widely investigated asset pricing models including (1) the standard Lucas (1978) constant relative risk aversion (CRRA) preference model, (2) the Epstein and Zin (1989) recursive preference model, and (3) the Campbell and Cochrane (1999) external habit formation model, we derive explicit testable relations between the momentum and contrarian profits and the intertemporal dependence of macroeconomic variables such as the consumption growth rate or the surplus consumption growth rate.

\subsection{Momentum and contrarian profits and return persistence}

For ease of exposition, we use the following definition of the momentum and contrarian strategies throughout the paper. Both trading strategies select stocks based on the realized returns during $J$ consecutive months in the past (the formation period), and hold the stocks for $K$ consecutive months in the future (the holding period). Specifically, at the beginning of the holding period, stocks are ranked on the basis of their returns during the formation period. Based on these rankings, stocks with the highest returns in the formation period are included in the winner portfolio and stocks with the lowest returns over the formation period constitute the loser portfolio according to a pre-determined selection criterion. ${ }^{5}$ We equally weight the stocks in each portfolio.

The momentum strategy takes a long position in the winner portfolio and a short position in the loser portfolio, and holds this winner-minus-loser (WML) portfolio for the

\footnotetext{
${ }^{5}$ We use ten decile portfolios in our analysis. However, our results are robust to different selection
} 
next $K$ months. The return associated with this strategy is called the momentum profit. On the other hand, the contrarian strategy takes a long position in the loser portfolio and a short position in the winner portfolio, and holds this loser-minus-winner (the reversal of the WML) portfolio for the holding period. This strategy generates a holding period return referred to as the contrarian profit. As the contrarian return is the opposite of the momentum return with the exception of the horizon of the formation period, we investigate the contrarian profit as the negative return to a momentum strategy conducted over a longer formation period than that for the momentum strategy.

Throughout the paper, we refer to the formation period as time $t-f$ and the holding period as time $t+h$ (both $f$ and $h$ are strictly greater than 0 ) without being specific about the exact month, except when we discuss the dataset. When a distinction between the momentum strategy and the contrarian strategy is required, we refer to the formation period as time $t$-fm and the holding period as time $t+h m$ for momentum trading, and the formation period as time $t-f c$ and the holding period as time $t+h c$ for contrarian trading. We denote the total return of stock $i$ in the formation period as $r_{i, t-f}$, the total return in the holding period as $r_{i, t+h}$, the formation period market return as $r_{m, t-f}$, the holding period market return as $r_{m, t+h}$, the total return on the WML portfolio in the formation period as $r_{W M L, t-f}$, and the total return of the WML portfolio in the holding period as $\pi_{t+h}$.

Cochrane (2001) suggests that momentum profit results from the interaction between the formation period winner-loser return dispersion and the small predictability of individual stock returns. Following this direction, we introduce a return persistence for the cross section of stocks. We then relate momentum and contrarian profits to the return persistence and the realized returns of winner and loser portfolios in the formation period. By studying the common return persistence of individual stock returns directly, we circumvent the need to identify and estimate different factors and stock-specific components. Consequently, we generate the momentum and contrarian profits without making onerous assumptions about the return generating process.

We specify the following form of intertemporal return dependence for the crosssection of stock returns

$$
r_{i, t+h}=a_{t+h}+b_{t+h} r_{i, t-f}+\varepsilon_{i, t+h},
$$

thresholds. 
where $a_{t+h}$ and $b_{t+h}$ are time-varying coefficients that are identical across individual stocks and $\varepsilon_{i, t+h}$ is the error term and is uncorrelated with the cross-section of stock returns $\left(r_{i, t-f}\right)$. This specification defines the conditional distribution of $r_{i, t+h}$ as a function of the cross-section of stock returns $\left(r_{i, t-f}\right)$. In particular, the slope coefficient, $b_{t+h}$, which is referred to as the return persistence, reflects a common level of return persistence, or the expected return persistence of a randomly selected stock at time $t+h$. It states that a cross-section of stock returns co-moves in the holding period and extends returns in the formation period in a linear but time-varying fashion.

The common return persistence can be viewed as an "average" serial correlation coefficient for the cross section of stock returns (a commonality in the persistence of stock returns). It summarizes the degree to which the cross-section of past returns is extended into the future. We use this specification of return persistence coupled with the selection of past winners and losers to generate momentum and contrarian profits. In particular, $b_{t+h}$ plays a key role in projecting returns from the formation period to the holding period.

Specification (1) is consistent with Conrad and Kaul (1998) in that it emphasizes the importance of selection to generate momentum profit. However, there is a difference between the selection mechanism in Conrad and Kaul (1998) and ours. Instead of examining the total returns in the formation period, they directly investigate the returns in the holding period, and thus auxiliary assumptions on the unconditional expected returns are required to identify the selection. In contrast, we relate the momentum profit to the conditional information of the formation period returns, and therefore establish the relation between the selection and the momentum profits with fewer restrictive assumptions about the underlying return generating process.

Because of the selection, the conditional mean of the WML portfolio in the holding period is different from the unconditional mean of the portfolio. When there is a return persistence between the formation and the holding periods, the return differential between the winner and loser portfolios in the formation period implies a selection return in the holding period. Thus, we formulate the expected return of the WML portfolio in the holding period as the product of the common return persistence coefficient $b_{t+h}$ and the formation period return of the WML portfolio 


$$
r_{W M L, t+h}=b_{t+h} \times r_{W M L, t-f}+e_{t+h},
$$

where $e_{t+h}$ is the mean zero statistical error. This relation holds for both the momentum and the contrarian profits as the persistence parameter $b_{t+h}$ adopts $b_{t+h m}$ for momentum trading and $b_{t+h c}$ for contrarian trading.

The formulation of the expected return of the WML portfolio given in equation (2) allows us to reconcile the momentum/contrarian profits of DeBondt and Thaler (1985) and Jegadeesh and Titman (1993) with the momentum/contrarian profits of Lo and Mackinlay (1990) and Conrad and Kaul (1998). ${ }^{6}$ To achieve this, we allow the crosssectional return persistence parameter $b_{t+h}$ to take the following expression in estimation

$$
b_{t+h}=\frac{\sum_{i}\left[\left(r_{i, t-f}-r_{m, t-f}\right) r_{i, t+h}\right]}{\sum_{i}\left(r_{i, t-f}-r_{m, t-f}\right)^{2}},
$$

where $r_{m, t-f}$ represents the average return for the cross-section of stocks of the formation period and $\sum_{i}\left[\left(r_{i, t-f}-r_{m, t-f}\right) r_{i, t+h}\right]$ yields the momentum profit in Conrad and Kaul (1998). Equation (2) therefore suggests that the momentum profits in Jegaddesh and Titman (1993), Debondt and Thaler (1985), and Conrad and Kaul (1998) differ only by a conditional known constant $\left(r_{W M L, t-f} / \sum_{i}\left(r_{i, t-f}-r_{m, t-f}\right)^{2}\right)$.

Because the intertemporal return dependence applies to the entire cross-section of stocks, it also applies to the market portfolio. Given the formation period returns and the intertemporal dependence parameters $a_{t+h}$ and $b_{t+h}$, the return of the equally-weighted market portfolio in the holding period can be expressed as a linear function of the formation period market returns (denoted as $r_{m, t-f}$ ). That is,

$$
r_{m, t+h}=a_{t+h}+b_{t+h} \times r_{m, t-f} .
$$

The equality holds because the equally-weighted market portfolio represents a simple cross-sectional aggregation of equation (1) and the idiosyncratic error term disappears because of the aggregation.

\footnotetext{
${ }^{6}$ Moskowitz and Grinblatt (1999) also show that the two forms of momentum profit are essentially the same.
} 
This specification decomposes the expected return of the market portfolio into a persistence-related component $\left(b_{t+h} r_{m, t-f}\right)$ and a non-persistence-related component $\left(a_{t+h}\right)$. The decomposition suggests that the market return consists of a component exhibiting short-term persistence that is common to all stocks. The existence of a persistent component in market return dynamics and the role it plays in generating the momentum and contrarian profits suggest that these effects can be attributed to broad market economic activities.

\subsection{Return persistence and macroeconomic fundamentals}

To establish the relation between the return persistence of the cross-section of stocks and macroeconomic fundamentals, we focus on the stochastic discount factor. Under the no-arbitrage principal, Harrison and Kreps (1979) show that there exists a stochastic discount factor which can be used to price financial assets. Thus, certain conditions must be satisfied for the stochastic discount factor to accommodate the return persistence. Indeed, by imposing a return persistence in the cross-section of stocks, we identify the restrictions on the intertemporal dependence in the stochastic discount factor. We summarize these restrictions as follows.

Proposition 1: Suppose that the co-movement of the cross-section of stock returns can be represented by $r_{i, t+h}=a_{t+h}+b_{t+h} r_{i, t-f}+\varepsilon_{i, t+h}, h, f>0$. Denote the stochastic discount factor at time $t$ as $s_{t}$ such that $E_{t}\left[s_{t+h} \times\left(1+r_{i, t+h}\right)\right]=1$. Under the no arbitrage condition, we have (1) $E_{t}\left(s_{t+h} \times b_{t+h}\right)=0$ and (2) $E_{t}\left[s_{t+h} \times\left(1+a_{t+h}\right)\right]=1$.

Existing studies have documented that a stochastic discount factor is a function of economic fundamentals such as the consumption growth rate. This allows us to derive restrictions on the macroeconomic fundamentals induced by the return persistence. To directly relate the momentum and contrarian profits to macroeconomic fundamentals, we assume that the logarithmic stochastic discount factor has a time-varying intertemporal dependence structure that is given by

$$
\ln s_{t+h}=\lambda_{t+h}+\kappa_{t+h} \ln s_{t-f}
$$

where $\lambda_{t+h}$ and $\ln s_{t-f}$ are conditionally independent, i.e., $E_{t}\left(\lambda_{t+h} \mid \ln s_{t-f}\right)=E_{t}\left(\lambda_{t+h}\right)$. 
Because we do not impose any structure on the coefficient $\kappa_{t+h}$, this assumption is not as restrictive as it may seem. Indeed, if the logarithm of the stochastic discount factor follows a Gaussian distribution, then a linear structure in the form of equation (5) follows directly.

If we further assume that there exists a linear spanning on the cross-section of stock returns $r_{i, t}$ such that $\ln s_{t}=\varpi_{t-1} \bullet r_{t}$ for all time $t$, where $\varpi_{t-1}$ and $r_{t}$ denote the vectors of the cross-sectional weights and returns, respectively, ${ }^{7}$ and the weights for the linear spanning are stable locally, that is, $\varpi_{t+h-1} \approx \varpi_{t-f-1}$, then the law of motion for the cross-section of stock returns $r_{i, t+h}=a_{t+h}+b_{t+h} r_{i, t-f}+\varepsilon_{i, t+h}$ implies that

$$
\ln s_{t+h} \approx w_{t-f-1} a_{t+h}+b_{t+h} \ln s_{t-f}
$$

as $E_{t+h}\left(\varpi_{t-f-1} \bullet \varepsilon_{t+h} \mid r_{t-f}\right)=0$, where $w_{t-f-1}=\sum_{i} \varpi_{i, t-f-1}$. In other words, under some mildly restrictive assumptions the parameters $\lambda_{t+h}$ and $\kappa_{t+h}$ that govern the stochastic discount factor are related to the return persistence parameters $a_{t+h}$ and $b_{t+h}$. In particular, comparing equations (5) and (6), we observe that the return persistence parameter $b_{t+h}$, which drives both the momentum and contrarian profits, is directly related to the intertemporal dependence parameter $\kappa_{t+h}$ for the stochastic discount factor. Although a more general relationship between $b_{t+h}$ and $\kappa_{t+h}$ is possible, the following proposition summarizes the testable restriction on the stochastic discount factor under the assumption that $b_{t+h}=\kappa_{t+h}$.

Proposition 2: Assume that conditions in Proposition 1 hold. Assume that the stochastic discount factor has a time-varying intertemporal dependence structure that is given by $\ln s_{t+h}=\lambda_{t+h}+\kappa_{t+h} \ln s_{t-f}$, where $E_{t}\left(\lambda_{t+h} \mid \ln s_{t-f}\right)=E_{t}\left(\lambda_{t+h}\right)$. When $b_{t+h}=\kappa_{t+h}$, the following condition holds

$$
E_{t} \ln s_{t+h}=E_{t}\left(-a_{t+h}-a_{t+h} \ln s_{t+h}-\left(\ln s_{t+h}\right)^{2} / 2+b_{t+h} \ln s_{t-f}\right),
$$

or as a first-order approximation we have

$$
E_{t} \ln s_{t+h}=E_{t}\left(-a_{t+h}+b_{t+h} \ln s_{t-f}\right) .
$$

\footnotetext{
7 This assumption follows the convention in finance literature which use asset returns as risk factors. For example, Fama and French (1996) form their systematic factors (SMB and HML) using a collection of
} 
Proposition 2 indicates that under the assumption of a linear dependence structure for the stochastic discount factor, the relation between the momentum/contrarian profits and the stochastic discount factor can be tested as a constraint given by equation (7). In other words, as long as this constraint holds, the intertemporal dependence pattern similar to that found in the cross-section of stock returns should also exist in the stochastic discount factor.

We next derive explicit testable restrictions on the stochastic discount factors for three widely examined asset pricing models. Our focus here is to establish the relation between the momentum/contrarian profits and the intertemporal dependence in macroeconomic fundamentals.

\section{Case 1: Lucas (1978) constant relative risk aversion model (CRRA)}

Consider a representative agent exchange economy with the constant relative risk aversion preference as in Lucas (1978). The logarithm of the stochastic discount factor takes the form $\ln s_{t}=\ln \beta-\gamma g_{t}$, where $\beta$ represents the time discount factor, $\gamma$ is the coefficient of relative risk aversion, and $g_{t} \equiv \ln \left(C_{t} / C_{t-1}\right)$ denotes the aggregate consumption growth rate at time $t$.

Corollary 1: Assume that all conditions in Proposition 2 hold. With the CRRA preference, equation (7) in Proposition 2 can be rewritten as

$$
E_{t} g_{t+h}=E_{t}\left[\frac{a_{t+h}}{\gamma}+\left(1-b_{t+h}\right) \frac{\ln \beta}{\gamma}+b_{t+h} g_{t-f}\right]+E_{t}\left[\frac{a_{t+h} \ln s_{t+h}}{\gamma}+\frac{\left(\ln s_{t+h}\right)^{2}}{2 \gamma}\right] .
$$

\section{Case 2: Epstein-Zin recursive preference model}

Consider a representative agent with the recursive preferences of Epstein and Zin (1989) and Weil (1989). For these preferences, the logarithm of the stochastic discount factor takes the form (see Bansal and Yaron, 2004):

$$
\ln s_{t}=\theta \ln \beta-\frac{\theta}{\psi} g_{t}+(\theta-1) r_{m, t},
$$

where $g_{t}$ is the log consumption growth rate at time $t, r_{m, t}$ is the market return at time $t, \beta$ is the time discount factor, $\psi$ is the elasticity of intertemporal of substitution (EIS) parameter, and $\theta$ is a function of the risk reversion coefficient and the EIS parameter,

asset returns. Note also that this assumption is used to motivate Proposition 2. 
$\theta=\frac{1-\gamma}{1-1 / \psi}$

Corollary 2: Assume that all conditions in Proposition 2 hold. With the Epstein-Zin preference, equation (7) in Proposition 2 can be rewritten as

$$
E_{t}\left(g_{t+h}\right)=E_{t}\left[\psi a_{t+h}+\psi \ln \beta\left(1-b_{t+h}\right)+b_{t+h} g_{t-f}+\frac{1-\psi}{\gamma-1}\left(a_{t+h} \ln s_{t+h}+\left(\ln s_{t+h}\right)^{2} / 2\right)\right] .
$$

In the special case in which $\psi=1 / \gamma$, the Epstein-Zin recursive preference is reduced to the standard CRRA preferences.

\section{Case 3: Campbell and Cochrane (1999) external habit formation model}

We now consider the Campbell and Cochrane (1999) external habit formation model. Under the external habit formation preferences, the logarithm of the stochastic discount factor takes the form $\ln s_{t}=\ln \delta-\gamma\left(u_{t}-u_{t-1}+g_{t}\right)$, where $u_{t} \equiv \ln \left(\frac{C_{t}-X_{t}}{C_{t}}\right)$ is the $\log$ surplus consumption ratio, $X_{t}$ is the external habit, and $g_{t}$ is the log consumption growth rate.

Corollary 3: Assume that all conditions in Proposition 2 hold. With the external habit formation preference, equation (7) can be rewritten as

$$
\begin{aligned}
& E_{t}\left(u_{t+h}-u_{t+h-1}+g_{t+h}\right) \\
& =E_{t}\left[\frac{a_{t+h}}{\gamma}+\left(1-b_{t+h}\right) \frac{\ln \delta}{\gamma}+b_{t+h}\left(u_{t-f}-u_{t-f-1}+g_{t-f}\right)\right]+E_{t}\left[\frac{a_{t+h} \ln s_{t+h}+\left(\ln s_{t+h}\right)^{2} / 2}{\gamma}\right] .
\end{aligned}
$$

Note that $u_{t}-u_{t-1}+g_{t}=\ln \left(\frac{C_{t}-X_{t}}{C_{t-1}-X_{t-1}}\right)$ represents the surplus consumption growth rate. Momentum and contrarian profits under the external habit formation preference specification impose a restriction on the intertemporal dependence in the surplus consumption growth rate and reflect short-term continuation and the long-term reversal on this macroeconomic fundamental.

\section{Empirical Analysis and Discussions}

In this section, we provide an extensive empirical analysis on the relation between the momentum and contrarian profits and the macroeconomic fundamentals identified in the previous section. Specifically, we first estimate time-varying return 
persistence parameters and document the magnitudes of momentum and contrarian profits generated by the return persistence and the selection of past winners and losers. We then empirically test the restrictions imposed on the stochastic discount factor stated in Propositions 1 and 2 using the three asset pricing models and the macroeconomic fundamentals identified in Corollaries 1 to 3.

We use return data on stocks traded on the NYSE and AMEX from the Center for Research in Security Prices (CRSP) monthly return file for our empirical analysis. Our sample spans the period between January 1927 and December 2003. To study the momentum and contrarian profits, we focus on the six-month/six-month strategy $(J=K=$ 6), which Jegadeesh and Titman (1993) found representative of the momentum strategy. Specifically, at the beginning of each month $t$, the stocks are ranked into deciles based on the returns during the six-month formation period (month $t-6$ through month $t-1$ for the short-term momentum profit, and month $t$-60 through $t-55$ for the long-term contrarian profit). ${ }^{8}$

Based on these rankings, ten equally weighted decile portfolios are formed in which the top decile (P10) is the best performing (the winner portfolio) and the bottom decile (P1) is the worst performing (the loser portfolio). The momentum strategy calls for the investor to take a long position in the winner portfolio (P10) and a short position in the loser portfolio (P1), and holds the winner-minus-loser (WML) portfolio for the following six months (month $t$ through month $t+5$ ). On the other hand, the contrarian strategy calls for an investor to take a long position in the loser portfolio and a short position in the winner portfolio, and holds the loser-minus-winner portfolio for the following six months. Unlike Jegadeesh and Titman (2001), we do not roll over and rebalance the momentum portfolio. The trading profit $\pi_{t+h}$ at month $t$ refers to the compounded return over the six-month holding period of the WML portfolio.

We use aggregate real per capita consumption (nondurable and services) data to compute the aggregate consumption growth rate $\left(g_{t}\right)$. The dataset for the aggregate

\footnotetext{
${ }^{8}$ We adopt this convention to define the trading strategies so that we can match the quarterly observations of macroeconomic data. For the momentum strategy, some authors (Fama and French (1996)) skip the most recent month in their formation period, and produce slightly larger momentum profit. For the contrarian strategy, some authors use a longer formation period. For instance, Conrad and Kaul (1998) use month $t$-36 to $t-1$ and $t-24$ to $t-1$ as the formation periods and next 24 to 36 months as the holding period, DeBondt and Thaler (1985) use month $t$-36 to $t-1$ as the formation period and next 36 months as the holding periods, and Fama and French (1996) use past 13 to 60 months as the formation period and current month as the holding period. We note, however, that neither the addition of one-month gap in the case of the momentum strategy
} 
nondurable and services consumption data and the U.S. population data are obtained from the Federal Reserve Bank of St. Louis Web site. Our quarterly consumption growth rate starts in the second quarter of 1952 and ends in the fourth quarter of 2003. To match the time horizons of the return dependence and the macroeconomic dependence, for any quarter $t$ we denote the consumption growth rate for the next two consecutive quarters (the holding period) as $g_{t+h}$ and the growth rate of the past two consecutive quarters (the formation period) as $g_{t-f}$. For the momentum strategy, the past two consecutive quarters refer to the immediate past two quarters, or month $t-6$ to $t-1$, and for the contrarian strategy they refer to the two quarters that cover the months between $t-60$ and $t-55$. This gives rise to a sample period that runs from the third quarter of 1952 to the third quarter of 2003. For the intertemporal dependence parameters $a_{t+h}$ and $b_{t+h}$, we use the estimates for the NYSE and AMEX stocks that are reported in Section 3.1 below.

As demonstrated in Corollaries 1 to 3 , a particular restriction on the consumption growth rate or surplus consumption growth rate can be imposed depending upon specific preferences. A non-rejection of the restrictions stated in Propositions 1 and 2 indicates the ability of the asset pricing model in generating the observed momentum and contrarian profits. Because these restrictions are conditional nonlinear constraints, we can perform the conditional test using the generalized method of moments (GMM). For each stochastic discount factor discussed above, we follow Hansen and Singleton (1982) and form moment conditions as the basis for our GMM estimation. Specifically, we use the following instruments to interact with the aforementioned restrictions to form the orthogonality conditions: the unity vector, the equally weighted CRSP market index return $r_{m, t}$, the default spread $d e f_{t}$, the CRSP dividend yield $d i v_{t}$, the term spread term $_{t}$, and the short-term bond yield $y l d_{t}$. For the market index return, we use observations for the two quarters that cover month $t-6$ to month $t-1$. For the other four market-wide variables, we use the observations from month $t-1 .{ }^{9}$ Ferson and Harvey (1991) use this set of variables to describe the predictable time variation in the expected stock returns, while Chordia and Shivakumar (2002) utilize the same set of variables to capture the predictable time variation in the momentum profit.

nor lengthening the formation period in the case of the contrarian strategy changes our results.

9 We follow Chordia and Shivakumar (2002) in collecting these data. We experiment with other instrumental variables and find similar results (the results are not reported and are available upon request). 
Table 1 provides the summary statistics for the momentum and contrarian returns, the consumption growth rate, and five conditioning variables used in the GMM tests including the momentum return $\left(\pi_{t+h, m}\right)$, the contrarian return $\left(\pi_{t+h, c}\right)$, the bi-quarterly consumption growth rate $\left(g_{t+h}\right)$, and the conditioning variables for the GMM estimation: the market index return $\left(r_{m, t}\right)$, the default spread $\left(d e f_{t}\right)$, the dividend yield $\left(\operatorname{div}_{t}\right)$, the term spread $\left(\right.$ term $\left._{t}\right)$, and the short-term yield $\left(y l d_{t}\right)$.

\subsection{Empirical evidence for momentum/contrarian profits and return persistence}

To demonstrate the relation between the momentum/contrarian profits and the return persistence, for each month $t$ we estimate the parameters $a_{t+h m}$ and $b_{t+h m}$ for the momentum profit and the parameters $a_{t+h c}$ and $b_{t+h c}$ for the contrarian profit. Specifically, we perform the cross-sectional regression of the holding period stock returns (compounded over month $t$ to month $t+5$ ) on the formation period stock returns (compounded over month $t-6$ to month $t-1$ for the momentum strategy, and over month $t$ 60 to month $t-55$ for the contrarian strategy).

Table 2 reports the summary statistics of these parameter estimates including the respective mean and standard deviation of the estimates for $a_{t+h m}, b_{t+h m}, a_{t+h c}$ and $b_{t+h c}$, and the correlation between $a_{t+h}$ and $b_{t+h}$ for momentum trading (panel A) and contrarian trading (panel B) for the entire sample from July 1926 (January 1931 for the contrarian profit) to July 2003, the widely examined post-1947 sample from January 1947 to July 2003, and two subsamples of January 1947 to December 1977 and January 1978 to July $2003 .^{10}$

Our estimation results suggest that the non-persistence-related component $a_{t+h}$ is positive and highly statistically significant. For both momentum and contrarian regressions, the average coefficient estimate remains in a tight range between 0.066 and 0.089 for all sample periods. More important, there is a time-varying return persistence as indicated by the statistically significant average coefficient estimate for the regression slope $b_{t+h}$. This return persistence is positive at a short horizon (six months) as reflected

\footnotetext{
10 We choose the 1947 breakpoint to be consistent with Conrad and Kaul (1998), who point out that the momentum profit becomes significant only after 1947. Other breakpoints for the subsample periods are chosen so that the post-1947 sample period is equally split.
} 
by a positive average coefficient estimate for $b_{t+h m}$ and negative at a long horizon (five years) as indicated by a negative average coefficient estimate for $b_{t+h c}$. The average return persistence estimate at short horizon is 0.044 for the full sample and 0.067 for the sample after 1947. At long horizon, the average return persistence coefficient is -0.033 for the full sample and -0.02 for the sample after 1947. Further, the persistence component and the non-persistence component are negatively correlated. This suggests that if the non-persistence component dominates in certain time periods, the broad market stock returns may exhibit negative serial correlation.

In Figure 1 we plot the realized momentum and contrarian profits (the solid line on the left scale) and the predicted momentum and contrarian profits using equation (2) (the dashed line on the right scale) for the sample period from July 1926 to July 2003. Both the realized momentum profit (panel A) and the realized contrarian profit (panel B) track their predicted counterparts closely over time.

To investigate how well the momentum and contrarian profits implied by the return persistence and the selection mechanism track their realized counterparts $\left(b_{t+h} r_{W M L, t-f}\right)$, we conduct two tests. First, we examine the average difference between the realized and the predicted WML profit $\left(\pi_{t+h}-b_{t+h} \times r_{W M L, t-f}\right)$. Second, we perform the regression analysis

$$
\pi_{t+h}=c_{0}+c_{1} \times\left(b_{t+h} \times r_{W M L, t-f}\right)+e_{t+h}
$$

to quantify how much of the variability of the realized momentum/contrarian profits are explained by changes in the predicted momentum/contrarian profits.

Table 3 reports the average realized momentum/contrarian profits $\left(\operatorname{column} \pi_{t+h}\right)$, their predicted counterparts based on the return persistence and the selection $\left(b_{t+h} r_{W M L, t-f}\right)$, the difference between the realized and predicted momentum/contrarian profits, and the results of regressing the realized momentum/contrarian profits on their predicted counterparts. Panel A shows the results for the momentum profit. For the post-1947 subsample, the average realized momentum profit is $5.27 \%$ per six months, or $10.5 \%$ per annum. This is consistent with the finding reported in Jegadeesh and Titman (1993). ${ }^{11}$ For the full sample, the momentum profit is much lower at $2.4 \%$ per six

11 They use a dataset that includes NASDAQ stocks. However, they exclude firms with very small market capitalization and firms with a stock price that is lower than $\$ 5$. 
months or $4.8 \%$ per annum. The average predicted momentum profit is $5.2 \%$ for six months and $10.4 \%$ per annum, almost identical to its realized counterpart, based on the post-1947 sample estimates. It is slightly higher at 3.29\% per six months or $6.5 \%$ per annum than the realized counterpart when the full sample estimates are used. The difference between the average realized and predicted momentum profit is $0.07 \%$ per six months $(0.14 \%$ per annum) for the sample after 1947 , and is not statistically significant. For the full sample, the difference is $-0.89 \%$ per six months $(-1.78 \%$ per annum) and only marginally significant at the $5 \%$ level.

Panel B shows the results for the contrarian profit. For the sample after 1947, the average realized contrarian profit is significant at $1.22 \%$ per six months $(2.44 \%$ per annum), which is consistent with the results of Conrad and Kaul (1998). For the full sample, the average realized contrarian profit is $2.32 \%$ per six months $(4.64 \%$ per annum). The average predicted contrarian profit is $2.27 \%$ per six months $(4.5 \%$ per annum) based on the full sample estimates and $1.42 \%$ per six months ( $2.84 \%$ per annum) based on the sample estimates after 1947. Both are very close to their realized counterparts. For the contrarian strategy, the difference between the average realized and predicted profits is close to zero and insignificant across all sample periods, which is consistent with specification (2).

Further, in support of the return persistence and the selection mechanism, we find that for both the momentum and contrarian returns, the adjusted $\mathrm{R}^{2}$ for regression (12) ranges from $87 \%$ to $91 \%$ for both the full sample and the post-1947 subsample. This indicates that a large fraction of the realized momentum/contrarian profit variability can be explained by the changes in predicted momentum/contrarian profits. With the exception of the momentum profit in the pre-1947 period, the intercept estimates are in general insignificantly different from zero, and the slope estimates are in general insignificantly different from one. These results therefore support the specification that the interaction of the return persistence and the selection generates the level of momentum/contrarian profits observed in the data.

Specification (4) decomposes the market return into a non-persistence component $a_{t+h}$ and a persistence component $b_{t+h} \times r_{m, t-f}$. To link the momentum and contrarian profits to macroeconomic variables, we now examine the persistence in the market return. Similar to the analysis on individual stock returns, we first examine the average 
difference between the realized market return and the predicted market return based on specification (4). We then investigate how much of the variation in the market return can be explained by the persistence and non-persistence components using the regression

$$
r_{m, t+h}=c_{0}+c_{1} \times a_{t+h}+c_{2} \times\left(b_{t+h} \times r_{m, t-f}\right)+e_{m, t+h}
$$

where the parameters $a_{t+h}$ and $b_{t+h}$ are estimated under the momentum and the contrarian trading strategies, respectively.

Table 4 reports the time-series average for the realized market return $\left(r_{m, t+h}\right)$, the persistence component of the market return $b_{t+h} \times r_{m, t-f}$, the difference between the realized market return and the predicted market return $\left(a_{t+h}+b_{t+h} \times r_{m, t-f}\right)$, and the results of regressing the realized market return $r_{m, t+h}$ on the non-persistence component $\left(a_{t+h}\right)$ and the persistence component of the market return, i.e.,

$$
r_{m, t+h}=c_{0}+c_{1} \times a_{t+h}+c_{2} \times\left(b_{t+h} \times r_{m, t-f}\right)+e_{t+h},
$$

where $r_{m, t-f}$ denotes the compounded market return in the formation period (month $t-6$ to $t-1$ for the momentum strategy (Panel A), and month $t-60$ to $t-55$ for the contrarian strategy (Panel B)). The average realized six-month market return is $8.29 \%$ for the full sample and $7.51 \%$ for the sample after 1947. In the meantime, the average persistence component of the market return is statistically significant at $0.7 \%$ per six months $(1.4 \%$ per annum) for the full sample and $0.5 \%$ per six months ( $1 \%$ per annum) for the sample after 1947, respectively. The difference between the realized market return and the predicted market return is $0.58 \%$ per six months for the full sample for both the momentum and the contrarian strategies, and is considerably lower at $0.14 \%$ and $0.2 \%$ for the sample after 1947, respectively. Although the difference is statistically significant for the momentum strategy for both the full sample and post-1947 subsample, it is very small relative to the overall realized market return. For the contrarian strategy the estimated difference is only significant for the full sample, but not for the sample after 1947.

For the equally weighted market portfolio, the adjusted R-squared should be one, because the equally-weighted market portfolio is simply an average of all of the individual stocks. The regression results show that the adjusted R-squared are consistently above $98 \%$ across all samples and for both the momentum and contrarian 
strategies. ${ }^{12}$ The coefficient estimates are in general consistent with the hypothesis that the predicted market return based on $a_{t+h}$ and $b_{t+h} \times r_{m, t-f}$ is equal to the realized market return. The estimated intercept coefficient is close to zero, and the slope coefficient is close to one. The pre-1947 sample deviates slightly from the predicted values, but the deviations are generally small.

Our decomposition of the market returns into the persistence and non-persistence components offers additional insight into the seemingly inconsistent relation between the short-term momentum profit that is generated from individual stock returns and the negative serial correlation at six month frequency for the market returns that is documented in existing empirical studies (Lewellen (2002)). We uncover that the shortterm continuation in the market return is captured by the persistence component $\left(b_{t+h} \times r_{m, t-f}\right)$ which exhibits a positive serial correlation. The non- or slightly negative autocorrelation in the market return is caused by the non-persistence component $\left(a_{t+h}\right)$, which is weakly negatively correlated with the market return in the formation period. Therefore, the short-term return continuation as demonstrated by the momentum of individual stock returns can co-exist with the negative serial correlation for the market index return.

\subsection{Empirical evidence on the relation between the momentum and contrarian profits and macroeconomic fundamentals}

We now investigate the relation between the momentum and contrarian profits and the macroeconomic fundamentals by empirically testing the implications of Propositions 1 and 2 focusing on the three widely applied asset pricing models. We summarize the three restrictions on the stochastic discount factor as follows:

(I) $E_{t}\left(s_{t+h} \times b_{t+h}\right)=0$,

(II) $E_{t}\left[s_{t+h} \times\left(1+a_{t+h}\right)\right]=1$, and

(III) $E_{t} \ln s_{t+h}=E_{t}\left[-a_{t+h}-a_{t+h} \ln s_{t+h}-\left(\ln s_{t+h}\right)^{2} / 2+b_{t+h} \ln s_{t-f}\right]$.

Restriction (I) ensures the rationality of the observed return continuation/reversal parameter $b_{t+h}$. Restriction (II) ensures the rationality of the non-persistence component of the market return $a_{t+h}$. Restriction (III) tests the relation between the return

12 The less than perfect fit may be partially due to minor non-linearity of the specification (1). 
persistence and the intertemporal dependence of the macroeconomic fundamentals. Further, a non-rejection of restrictions (I), (II), and (III) jointly suggests that the momentum and contrarian profits manifest the short-term continuation and long-term reversal of macroeconomic fundamentals.

Tables 5, 6, and 7 present the GMM estimation results for the restrictions on the macroeconomic fundamentals for the CRRA, the Epstein-Zin recursive preference, and external habit formation preference models, respectively. In each table, we report the estimation results for all three restrictions jointly for the short-term return dependence (under column "Momentum"), the long-term return dependence (under column "Contrarian"), and both the short-term and the long-term return dependence simultaneously (under column "Momentum \& Contrarian").

The empirical results in Table 5 suggest that the restrictions have empirical support under the CRRA model for the short-term and/or the long-term return dependence. The p-values for the $J$-test (the over-identification test for the specification) are consistently above $8 \%$ for all three return dependence scenarios ("Momentum", "Contrarian", and "Momentum \& Contrarian"). The estimated risk aversion coefficient ranges from 5.2 to 6.9 and is higher than the value that is considered to be reasonable. This is consistent with the widely documented equity premium puzzle under the CRRA preferences. The estimates for the time discount factor range from 0.989 to 1.007 , in line with estimates of the discount factor reported in some existing studies such as Kocherlakota (1990).

The GMM estimation for the Epstein-Zin recursive preference model in Table 6 shows similar results to that under the CRRA model. The $J$-test again indicates nonrejection of the three restrictions with p-values above 21 percent for all three intertemporal dependence scenarios. The estimate of the time discount factor ranges from 1.09 to 1.17 and is higher than that under the CRRA model. On the other hand, the estimate for the risk aversion coefficient is reduced to the range between 1.8 and 3.5 and considered to be more reasonable on agents' risk aversion.

The estimation results also indicate that we need a low EIS parameter $(\psi)$ to fit the restrictions. Specifically, the EIS estimate ranges from 0.07 to 0.15 for all three intertemporal dependence scenarios. Kandel and Stambaugh (1991) report that to match the observed market index return predictability in both the short term and the long term, the EIS parameter for the Epstein-Zin recursive preferences must be very close to zero. 
Our EIS estimates are consistent with their finding and remain small across all three scenarios of intertemporal dependences.

The external habit formation model used here follows Campbell and Cochrane (1999) in assuming the latent process of the quarterly log surplus consumption ratio to be AR(1). The $J$-test again indicates non-rejection of the restrictions across all three intertemporal dependence scenarios. The p-values for the $J$-test range from $6 \%$ for the short-term intertemporal dependence to $60 \%$ for both the short-term and long-term intertemporal dependences. In addition to the time discount parameter and the curvature parameter $(\gamma)$, we also estimate the parameter that governs the persistence of the log surplus consumption ratio $(\phi) .{ }^{13}$

To match the observed stock market returns, Campbell and Cochrane (1999) use a curvature parameter of 2.0, and our estimated value ranges from 4.2 to 5.9 to fit all three restrictions across all scenarios of return dependence. For the time discount factor, Campbell and Cochrane (1999) use a value of 0.89 for the monthly frequency. Our estimated time discount factor varies between 0.72 and 0.91 for the six-month frequency, which corresponds to a monthly value of about 0.95 to 0.98 . For the persistence parameter $(\phi)$, they use a value of 0.87 for a monthly specification. Our estimate of the persistence parameter ranges from 0.84 to 0.88 which are very close to the value used in Campbell and Cochrane (1999). Tallarini and Zhang (2005) use the efficient method of moments to estimate the model of Campbell and Cochrane (1999). They report a curvature parameter estimate of 6.27 , a time discount factor estimate of 1.007 , and a persistence parameter estimate of 0.912 for the quarterly data. Our results are generally consistent with theirs.

Overall, our GMM estimation results support the hypothesis that there is a close relation between the momentum and contrarian profits and the macroeconomic fundamentals, in this case the consumption growth rate and/or the surplus consumption growth rate. The widely documented momentum and contrarian profits manifest the short-term continuation and the long-term reversal of the macroeconomic fundamentals.

\subsection{Robustness check using alternative unconditional regression analysis}

\footnotetext{
13 In our estimation, we require the stochastic discount rate to be less than 250 . With a value of 250 for the stochastic discount factor at any in-sample data point, the sample volatility of the stochastic discount factor is at least 15 . This restriction therefore is quite reasonable.
} 
Our theoretical discussions suggest that if we omit the higher-order terms and focus on the first-order approximation of restriction III, we arrive at the following linear relations under various economic models:

The Lucas CRRA model

$$
E_{t} g_{t+h}=E_{t}\left[\frac{a_{t+h}}{\gamma}+\frac{\ln \beta}{\gamma}\left(1-b_{t+h}\right)+b_{t+h} g_{t-f}\right]
$$

The Epstein-Zin recursive preference model

$$
E_{t}\left(g_{t+h}\right)=E_{t}\left[\psi a_{t+h}+\psi \ln \beta\left(1-b_{t+h}\right)+b_{t+h} g_{t-f}\right]
$$

The Campbell-Cochrane external habit formation model

$$
E_{t}\left(u_{t+h}-u_{t+h-1}+g_{t+h}\right)=E_{t}\left[\frac{a_{t+h}}{\gamma}+\left(1-b_{t+h}\right) \frac{\ln \delta}{\gamma}+b_{t+h}\left(u_{t-f}-u_{t-f-1}+g_{t-f}\right)\right] .
$$

The above conditions allow us to perform an alternative unconditional test on the relation between the return persistence and the macroeconomic fundamentals using regression analysis. Specifically, for both the CRRA and the Epstein-Zin recursive preference models, the first-order approximation can be tested using the following linear regression specification:

$$
g_{t+h}=c_{0}+c_{1} \times a_{t+h}+c_{2} \times\left(1-b_{t+h}\right)+c_{3} \times b_{t+h} g_{t-f}+e_{t+h} .
$$

Both the CRRA and Epstein-Zin recursive preference models impose restrictions on the parameters $c_{0}, c_{1}, c_{2}$, and $c_{3}$. Specifically, for the CRRA model, we have $c_{0}=0$, $c_{1}=\frac{1}{\gamma}, c_{2}=\frac{\ln \beta}{\gamma}$, and $c_{3}=1$. For the Epstein-Zin model, we have $c_{0}=0, c_{1}=\psi$, $c_{2}=\psi \ln \beta$, and $c_{3}=1$. Under the first-order approximation, the two specifications are isomorphic in the unconditional regression analysis. A joint hypothesis of no relation between the return persistence and the intertemporal dependence of the consumption growth rate can be stated as follows:

$$
H_{0}: c_{1}=0 \text { and } c_{3}=0 .
$$

The rejection of (18) then supports the alternative hypothesis that there is a relation between the return persistence and the intertemporal dependence of the consumption growth rate.

For the Campbell-Cochrane external habit formation model, we use the following regression specification to test the relation between the return persistence and the 
intertemporal dependence of the surplus consumption growth rate:

$$
g c s_{t+h}=c_{0}+c_{1} \times a_{t+h}+c_{2} \times\left(1-b_{t+h}\right)+c_{3} \times\left(b_{t+h} \times g c s_{t-f}\right)+e_{t+h}
$$

where $g c s_{t}=u_{t}-u_{t-1}+g_{t}$ represents the surplus consumption growth rate. Because the habit level is not directly observable, we simulate the latent log surplus consumption ratio observations using the parameters that are estimated by the GMM with the three joint restrictions I, II, and III under both the short-term and the long-term return dependence scenarios as reported in Table 7. Combining the latent log surplus consumption ratio observations and the observed consumption growth rates, we generate the surplus consumption growth rates. The Campbell-Cochrane external habit model imposes restrictions on four parameters $c_{0}=0, c_{1}=\frac{1}{\gamma}, c_{2}=\frac{\ln \beta}{\gamma}$, and $c_{3}=1$. The same joint hypothesis as stated in (18) allows us to test the relation between the return persistence and the intertemporal dependence of the surplus consumption growth rate.

Tables 8 and 9 present the results of the regression analysis based on the firstorder approximation of restriction III for the CRRA and Epstein-Zin recursive preference models (Table 8) and the Campbell-Cochrane external habit formation model (Table 9), respectively. We report results for the short-term dependence (under column "Momentum") and the long-term return dependence (under column "Contrarian") for the full sample from 1952Q4 to 2003Q3 and two sub-sample periods (1952Q4-1977Q4 and 1978Q1-2003Q3). For the CRRA and the Epstein-Zin recursive preference models, the joint hypothesis stated in (18) is rejected at the 5\% test level for the full sample for both the short-term and the long-term intertemporal return dependence. Further, the estimate of $c_{0}$ is insignificantly different from zero. The estimate of $c_{1}$ is small, which reflects a high risk aversion or low intertemporal elasticity of substitution. The estimate of $c_{2}$ is in general very small, which is consistent with a time discount factor that is close to one. The estimate of $c_{3}$ is insignificantly different from one, as predicted by the model, and statistically different from zero in most cases.

For the Campbell-Cochrane external habit formation model, the estimate of $c_{0}$ remains statistically insignificant across both return dependence scenarios for all sample periods. The estimate for the inverse curvature parameter $c_{1}$ suggests that the curvature parameter ranges from 1.62 (or 1/0.6186) to 1.83 (or 1/0.5497) and is lower than the 
estimate reported in Table 7. The estimate of $c_{2}$ is insignificant, which indicates a time discount factor that is close to one. The estimate of $c_{3}$ is insignificantly different from one but significantly different from zero, as predicted by the model.

Overall, the results based on the unconditional regression analysis are consistent with the conditional test results using the GMM. They provide supporting evidence for the relation between the return persistence and the intertemporal dependence of macroeconomic fundamentals.

\section{Conclusion}

We demonstrate that the existence of the momentum and contrarian profits imposes restrictions on the dynamics of macroeconomic fundamentals such as the consumption growth rate and/or the surplus consumption growth rate. Specifically, the intertemporal dependence in macroeconomic fundamentals generates a return persistence which captures the co-movement of individual stock returns. The momentum and contrarian profits can then be attributed to the interaction of the return persistence and the selection of past winners and losers.

For three widely investigated asset pricing models including the CRRA preferences, the Epstein-Zin recursive utility, and the Campbell-Cochrane external habit formation models, we derive explicit testable restrictions on the intertemporal dependence of macroeconomic fundamentals such as the consumption growth rate and/or the surplus consumption growth rate.

Our empirical analysis shows strong support for the momentum and contrarian profits being characterized jointly by the return persistence and the selection of past winners and losers. When decomposing market returns into persistence and nonpersistence components, we provide an explanation for the co-existence of a negative serial correlation for the market returns and abnormal returns to momentum trading strategy.

Using the generalized method of moments, we formally test the relation between the momentum and contrarian profits and the macroeconomic fundamentals. For all three asset pricing models, our results indicate that the restrictions imposed on the macroeconomic fundamentals cannot be rejected. This suggests that the momentum and contrarian profits manifest the short-term continuation and the long-term reversal of 
macroeconomic fundamentals.

In the short run, the profits from holding the winner-minus-loser portfolio reflect the average positive intertemporal dependence in the macroeconomic fundamentals. In the long run, the profits reflect the reversal in the macroeconomic fundamentals. Momentum and contrarian trading strategies therefore amount to participation in macroeconomic fluctuations that are intertemporally dependent. The profits of the momentum and contrarian strategies are derived from the ability of these strategies to ride upon the stochastic variation of macroeconomic fundamentals. 


\section{Appendix: Collection of proofs}

Proof of Proposition 1: The existence of the stochastic discount factor follows from Harrison and Kreps (1979). The return persistence parameter $b_{t+h}$ given in Equation (3) suggests that it can be replicated with the trading strategy in Lo and MacKinlay (1990) scaled by a conditionally known constant. Because the trading strategy requires zero setup costs, under the no-arbitrage principle we must have $E_{t}\left(s_{t+h} \times b_{t+h}\right)=0$. Further, substituting the market return decomposition $r_{m, t+h}=a_{t+h}+b_{t+h} r_{m, t-f}$ into $E_{t}\left[s_{t+h} \times\left(1+r_{m, t+h}\right)\right]=1$ we have $E_{t}\left[s_{t+h} \times\left(1+a_{t+h}\right)\right]=1$. Proposition 1 therefore summarizes the rationality of the momentum and contrarian returns in the Euler equations.

Q.E.D.

Proof of Proposition 2: From the fact that $E_{t}\left[s_{t+h} \times\left(1+a_{t+h}\right)\right]=1$ in Proposition 1, applying Taylor series expansion and omitting terms that multiply four small numbers, we have:

$$
E_{t}\left(\ln s_{t+h}\right)=E_{t}\left[-a_{t+h}-a_{t+h} \ln s_{t+h}-.5 *\left(\ln s_{t+h}\right)^{2}-\left(\ln s_{t+h}\right)^{3} / 6-.5 a_{t+h}\left(\ln s_{t+h}\right)^{2}\right] .
$$

In other words, we have:

$$
\begin{aligned}
& E_{t}\left(\lambda_{t+h}+\kappa_{t+h} \ln s_{t-f}\right) \\
& \quad=E_{t}\left[-a_{t+h}-a_{t+h} \ln s_{t+h}-.5 \lambda_{t+h}{ }^{2}-\lambda_{t+h} \kappa_{t+h} \ln s_{t-f}-\left(\ln s_{t+h}\right)^{3} / 6-.5 a_{t+h}\left(\ln s_{t+h}\right)^{2}\right]
\end{aligned}
$$

Under the assumption $\kappa_{t+h}=b_{t+h}$, Proposition 1 implies that $E_{t}\left(s_{t+h} \times \kappa_{t+h}\right)=0$.

Omitting the fourth-order terms we have:

$$
\begin{gathered}
E_{t}\left(\kappa_{t+h}+\kappa_{t+h} \lambda_{t+h}+\left(\kappa_{t+h}\right)^{2} \ln s_{t-f}+.5 * \kappa_{t+h}\left(\ln s_{t+h}\right)^{2}\right) \approx 0, \text { and } \\
\ln s_{t-f} \times E_{t}\left(\kappa_{t+h}+\kappa_{t+h} \lambda_{t+h}\right) \approx 0 .
\end{gathered}
$$

Using the above condition, we arrive at the following equation:

$$
E_{t}\left(\lambda_{t+h}\right)=E_{t}\left[-a_{t+h}-a_{t+h} \ln s_{t+h}-.5 \lambda_{t+h}{ }^{2}-\left(\ln s_{t+h}\right)^{3} / 6-.5 a_{t+h}\left(\ln s_{t+h}\right)^{2}\right] .
$$

The logarithm of the stochastic discount factor (SDF) can thus be written as:

$$
\begin{aligned}
E_{t} \ln s_{t+h} & =E_{t}\left(\lambda_{t+h}+\kappa_{t+h} \ln s_{t-f}\right) \\
& =E_{t}\left[-a_{t+h}-a_{t+h} \ln s_{t+h}-.5 \lambda_{t+h}{ }^{2}-\left(\ln s_{t+h}\right)^{3} / 6-.5 a_{t+h}\left(\ln s_{t+h}\right)^{2}+\kappa_{t+h} \ln s_{t-f}\right] .
\end{aligned}
$$


If we further omit the third-order terms, we have a second-order approximation:

$$
E_{t} \ln s_{t+h}=E_{t}\left(-a_{t+h}-a_{t+h} \ln s_{t+h}-\left(\ln s_{t+h}\right)^{2} / 2+b_{t+h} \ln s_{t-f}\right),
$$

or alternatively

$$
E_{t} \ln s_{t+h}=E_{t}\left[\left(-a_{t+h}-a_{t+h} \lambda_{t+h}-\left(\lambda_{t+h}\right)^{2} / 2\right)+\kappa_{t+h} \ln s_{t-f}\left(1-a_{t+h}\right)\right] .
$$

Given that $\ln s_{t-f}$ is in investors' information set at time $t$, the first-order approximation can be written as

$$
E_{t} \ln s_{t+h}=E_{t}\left(-a_{t+h}+\kappa_{t+h} \ln s_{t-f}\right)=E_{t}\left(-a_{t+h}+b_{t+h} \ln s_{t-f}\right) .
$$

Q.E.D.

Proof of Corollary 1: Plugging in the stochastic discount factor into $\ln s_{t+h}=\lambda_{t+h}+\kappa_{t+h} \ln s_{t-f}$, we have $\ln \beta-\gamma g_{t+h}=\lambda_{t+h}+\kappa_{t+h} \ln s_{t-f}$. Applying the result in Proposition 2 that $E_{t} \ln s_{t+h}=-E_{t}\left[a_{t+h}+a_{t+h} \ln s_{t+h}+\left(\ln s_{t+h}\right)^{2} / 2-b_{t+h} \ln s_{t-f}\right]$, we have:

$$
E_{t}\left(\gamma g_{t+h}\right)=E_{t}\left[a_{t+h}+\left(1-b_{t+h}\right) \ln \beta+a_{t+h} \ln s_{t+h}+\left(\ln s_{t+h}\right)^{2} / 2+\gamma b_{t+h} g_{t-f}\right] .
$$

In other words, we should have

$$
E_{t} g_{t+h}=E_{t}\left[\frac{a_{t+h}}{\gamma}+\left(1-b_{t+h}\right) \frac{\ln \beta}{\gamma}+b_{t+h} g_{t-f}+\frac{a_{t+h} \ln s_{t+h}}{\gamma}+\frac{\ln \left(s_{t+h}\right)^{2}}{2 \gamma}\right] .
$$

Similarly, we can explicitly work out the first-order approximation as

$$
E_{t} g_{t+h}=E_{t}\left[\frac{a_{t+h}}{\gamma}+\left(1-b_{t+h}\right) \frac{\ln \beta}{\gamma}+b_{t+h} g_{t-f}\right]
$$

Q.E.D.

Proof of Corollary 2:

Plugging the stochastic discount factor $\ln s_{t}=\theta \ln \beta-\frac{\theta}{\psi} g_{t}+(\theta-1) r_{m, t}$ into the condition of Proposition 2

$$
E_{t} \ln s_{t+h}=E_{t}\left[-a_{t+h}-a_{t+h} \ln s_{t+h}-\left(\ln s_{t+h}\right)^{2} / 2+b_{t+h} \ln s_{t-f}\right],
$$

we arrive at the following equation:

$$
\begin{aligned}
& E_{t}\left[\theta \ln \beta-\frac{\theta}{\psi} g_{t+h}+(\theta-1) r_{m, t+h}\right] \\
& =E_{t}\left\{-a_{t+h}-a_{t+h} \ln s_{t+h}-\left(\ln s_{t+h}\right)^{2} / 2+b_{t+h}\left[\theta \ln \beta-\frac{\theta}{\psi} g_{t-f}+(\theta-1) r_{m, t-f}\right]\right\}
\end{aligned}
$$

Collecting terms together, we have: 


$$
\begin{aligned}
& E_{t}\left(g_{t+h}\right) \\
& \quad=E_{t}\left[\psi a_{t+h}+\frac{\psi}{\theta}\left[a_{t+h} \ln s_{t+h}+\left(\ln s_{t+h}\right)^{2} / 2\right]+\psi \ln \beta\left(1-b_{t+h}\right)+b_{t+h} g_{t-f}+\psi \frac{1-\theta}{\theta} e_{m, t+h}\right],
\end{aligned}
$$

where $e_{m, t+h}=r_{m, t+h}-a_{t+h}-b_{t+h} \times r_{m, t-f}$ is the linear tracking error of the market return that is close to 0 . We also have $\frac{\psi}{\theta}=\frac{1-\psi}{\gamma-1}$ by definition. Combining these terms, we obtain the relationship.

The first-order approximation can be similarly derived as follows:

$$
E_{t}\left(g_{t+h}\right)=E_{t}\left[\psi a_{t+h}+\psi \ln \beta\left(1-b_{t+h}\right)+b_{t+h} g_{t-f}\right] .
$$

Q.E.D.

Proof of Corollary 3: Plugging the stochastic discount factor into the condition of Proposition 2 that $E_{t} \ln s_{t+h}=E_{t}\left[-a_{t+h}-a_{t+h} \ln s_{t+h}-\left(\ln s_{t+h}\right)^{2} / 2+b_{t+h} \ln s_{t-f}\right]$, we have:

$$
\begin{aligned}
& E_{t}\left(u_{t+h}-u_{t+h-1}+g_{t+h}\right) \\
& \quad=E_{t}\left[\frac{a_{t+h}+a_{t+h} \ln s_{t+h}+\left(\ln s_{t+h}\right)^{2} / 2}{\gamma}+\left(1-b_{t+h}\right) \frac{\ln \delta}{\gamma}+b_{t+h}\left(u_{t-f}-u_{t-f-1}\right)+b_{t+h} g_{t-f}\right] .
\end{aligned}
$$

The first-order approximation can be similarly derived as follows:

$$
E_{t}\left(u_{t+h}-u_{t+h-1}+g_{t+h}\right)=E_{t}\left[\frac{a_{t+h}}{\gamma}+\left(1-b_{t+h}\right) \frac{\ln \delta}{\gamma}+b_{t+h}\left(u_{t-f}-u_{t-f-1}+g_{t-f}\right)\right] .
$$

Q.E.D. 


\section{References}

Bansal, Ravi and Amir Yaron, 2004, Risks for the long run: A potential resolution of asset pricing puzzles, Journal of Finance, 59, 1481-1509.

Barberis, Nicholas, Andrei Shleifer, and Robert Vishny, 1998, A model of investor sentiment, Journal of Financial Economics, 49, 307-343.

Campbell, John Y. and John H. Cochrane, 1999, By force of habit: A consumption-based explanation of aggregate stock market behavior, Journal of Political Economy, 205-251.

Cecchetti, Stephen G., Pok-sang Lam, and Nelson Mark, 1990, Mean reversion in equilibrium asset prices, American Economic Review, 80, 398-418.

Chan, Louis, K.C., Narasimhan Jegadeesh, and Joseph Lakonishok, 1996, Momentum strategies, Journal of Finance, 51, 1681-1713.

Chordia, Tarun and Lakshmanan Shivakumar, 2002, Momentum, business cycle and time varying expected returns, Journal of Finance, 57, 985-1019.

Cochrane, John H., 2001, Asset Pricing, Princeton University Press.

Cooper, Michael J., Roberto C. Gutierrez Jr., and Allaudeen Hameed, 2004, Market states and momentum, Journal of Finance, 59, 1345-1366.

Conrad, Jennifer and Gautam Kaul, 1998, An anatomy of trading strategies, Review of Financial Studies, 11, 489-519.

Daniel, Kent and Sheridan Titman, 1997, Evidence on the characteristics of cross sectional variation in stock returns, Journal of Finance, 52, 1-33.

Daniel, Kent, David Hirshleifer, and Avanidhar Subrahmanyam, 1998, Investor psychology and security market under- and over-reaction, Journal of Finance, 53, 18391886.

DeBondt, Werner F.M., and Richard H. Thaler, 1985, Does the stock market overreact? Journal of Finance, 40, 793-805.

Epstein, Larry G. and Stanley E. Zin, 1989, Substitution, risk aversion, and the temporal behavior of consumption and asset returns: A theoretical framework, Econometrica, 57, 937-968.

Fama, Eugene F. and Kenneth R. French, 1996, Multifactor explanations of asset pricing anomalies, Journal of Finance, 51, 55-84.

Ferson, Wayne E., and Campbell Harvey, 1991, The variation of economic risk premiums, Journal of Political Economy, 99, 385-415.

George, Thomas J. and Chuan-yang Hwang, 2004, The 52-week high and momentum 
investing, Journal of Finance, 59, 2145-2176.

Griffin, John M., Susan Ji and Spencer J. Martin, 2003, Momentum investing and business cycle risk: Evidence from pole to pole, Journal of Finance, 58, 1515-1547.

Grinblatt, Mark and Bing Han, 2005, Prospect theory, mental accounting and momentum, Journal of Financial Economics, 78, 311-339.

Grundy, Bruce D. and Spencer J. Martin, 2001, Understanding the nature of risks and the sources of rewards to momentum investing, Review of Financial Studies, 14, 29-78.

Hamilton, James D., 1989, A new approach to the economic analysis of nonstationary time series and the business cycle, Econometrica, 57, 357-84.

Hansen, Lars P. and Kenneth J. Singleton, 1983, Stochastic consumption, risk aversion and the temporal behavior of asset returns, Journal of Political Economy, 91, 249-265.

Harrison, J. Michael, and David M. Kreps, 1979, Martingales and arbitrage in multiperiod securities markets, Journal of Economic Theory, 20, 381-408.

Hong, Harrison and Jeremy C. Stein, 1999, A unified theory of underreaction, momentum trading and overreaction in asset markets, Journal of Finance, 54, 2143-2184.

Jegadeesh, Narasimhan and Sheridan Titman, 1993, Returns to buying winners and selling losers: Implication for stock market efficiency, Journal of Finance, 48, 65-91.

Jegadeesh, Narasimhan and Sheridan Titman, 2001, Profitability of momentum strategies: An evaluation of alternative explanations, Journal of Finance, 56, 699-720.

Jegadeesh, Narasimhan and Sheridan Titman, 2002, Cross-sectional and time-series determinants of momentum returns, Review of Financial Studies, 15, 143-157.

Johnson, Timothy, 2002, Rational momentum effects, Journal of Finance, 57, 585-608.

Kandel, Shmuel and Robert F. Stambaugh, 1991, Asset returns and intertemporal preferences, Journal of Monetary Economics, 27, 39-71.

Jiang, George and Tong Yao, 2006, Dynamic factors and the source of momentum profits, Journal of Business \& Economic Statistics, forthcoming.

Kocherlakota, Narayana, 1990, On the "discount" factor in growth economies, Journal of Monetary Economics, 25, 43-47.

Korajczyk, Robert A., and Ronnie Sadka, 2004, Are momentum profits robust to trading cost? Journal of Finance, 59, 1023-1048.

Lakonishok, Josef, Andrei Shleifer and Robert W. Vishny, 1994, Contrarian investment, extrapolation, and risk, Journal of Finance, 49, 1541-1578. 
Lewellen, Jonathan, 2002, Momentum and autocorrelation in stock returns, Review of Financial Studies, 15, 533-63.

Liu, Laura X. L., Jerold B. Warner, and Lu Zhang, 2005, Momentum profits and macroeconomic risk, NBER working paper 11480.

Lo, Andrew W., and A. Craig MacKinlay, 1990, When are contrarian profits due to market overreaction? Review of Financial Studies, 3, 175-205.

Lucas, Robert E. Jr, 1978, Asset prices in an exchange economy, Econometrica, 46(6), 1429-45.

Mehra, Rajinish and Edward C. Prescott, 1985, The equity premium: A puzzle, Journal of Monetary Economics, 15, 145-161.

Moskowitz, Tobias J. and Mark Grinblatt, 1999, Do industries explain momentum? Journal of Finance, 54, 1249-1290.

Rouwenhorst, K. Geert, 1998, International momentum strategies, Journal of Finance, 53, 267-284.

Tallarini, Thomas D., Jr. and Harold H. Zhang, 2005, External habit and the cyclicality of expected stock returns, Journal of Business, 78, 1023-1048.

Weil, Philippe, 1989, The equity premium puzzle and the riskfree rate puzzle, Journal of Monetary Economics, 24, 401-421. 
Table 1

\section{Summary Statistics for Key Variables}

The table presents summary statistics for the momentum return $\left(\pi_{t+h, m}\right)$, the contrarian return $\left(\pi_{t+h, c}\right)$, the bi-quarterly consumption growth rate $\left(g_{t+h}\right)$, and the conditioning variables for the GMM estimation: the market index return $\left(r_{m, t}\right)$, the default spread $\left(d e f_{t}\right)$, the dividend yield $\left(d i v_{t}\right)$, the term spread $\left(\right.$ term $\left.m_{t}\right)$, and the short-term yield $\left(y l d_{t}\right)$. The momentum (contrarian) profit is defined as the compounded return (negative compounded return) of the WML portfolio for month $t$ to month $t+5$ for the trading strategy with a formation period over month $t-6$ to $t-1$ (month $t-60$ to $t-55$ for the contrarian strategy). The sample period spans from July 1926 to July 2003 (January 1931 to July 2003 for the contrarian strategy). The bi-quarterly consumption growth rate represents the consumption growth rate of every two quarters over sample period from 1952Q4 to 2003Q3. The market index return is the six-month CRSP value weighted market return over sample period from 1952Q4 to 2003Q3. Other macroeconomic variables also cover the sample period from 1952Q22 to 2003Q3. Please refer to the text to find an explanation on the macroeconomic variables.

\begin{tabular}{lccccc} 
& Mean & Median & Std & Min & Max \\
\hline$\pi_{t+h, m}$ & 0.0240 & 0.0510 & 0.2011 & -2.8538 & 0.6072 \\
$\pi_{t+h, c}$ & -0.0232 & -0.0108 & 0.1209 & 0.2940 & -1.1492 \\
$g_{t+h}$ & 0.0109 & 0.0106 & 0.0075 & -0.0133 & 0.0312 \\
$r_{m, t}$ & 0.0812 & 0.0751 & 0.1730 & -0.3241 & 0.7558 \\
$d e f_{t}$ & 0.0095 & 0.0081 & 0.0043 & 0.0034 & 0.0269 \\
$d i v_{t}$ & 0.0335 & 0.0329 & 0.0100 & 0.0145 & 0.0580 \\
term & 0.0134 & 0.0130 & 0.0119 & -0.0265 & 0.0442 \\
$y l d_{t}$ & 0.0525 & 0.0498 & 0.0284 & 0.0064 & 0.1549 \\
\hline
\end{tabular}


Table 2

Summary Statistics for Return Persistence Parameters

The time-varying parameters $a_{t+h}$ and $b_{t+h}$ are estimated for each month by regressing the crosssection of the holding period returns (compounded over month $t$ to month $t+5$ ) on the cross-section of the formation period returns (compounded over month $t-6$ to $t-1$ for the momentum strategy in Panel A, and compounded over month $t-60$ to $t-55$ for the contrarian strategy in Panel B). The sample covers all individual stocks traded in NYSE and AMEX. The standard errors are reported in parentheses. NeweyWest procedure is used to adjust the time-series persistence in these estimates. '*' indicates a $5 \%$ significance level and ' $* *$ ' indicates a $1 \%$ significance level.

\begin{tabular}{|c|c|c|c|c|c|}
\hline & \multicolumn{2}{|c|}{$a_{t+h}$} & \multicolumn{2}{|l|}{$b_{t+h}$} & \multirow{2}{*}{$\begin{array}{c}\operatorname{Corr}\left(a_{t+h}, b_{t+h}\right) \\
\text { Correlation }\end{array}$} \\
\hline & Mean & Std. & Mean & Std. & \\
\hline & & Panel A. & Momentum Strategy & & \\
\hline $\begin{array}{l}1926.07- \\
2003.07\end{array}$ & $\begin{array}{l}0.0701 * * \\
(0.0128)\end{array}$ & $\begin{array}{c}0.1884 * \\
(0.0884)\end{array}$ & $\begin{array}{l}0.0439 * * \\
(0.0111)\end{array}$ & $\begin{array}{c}0.1945 \\
(0.1098)\end{array}$ & $\begin{array}{l}-0.3043 * * \\
(0.0737)\end{array}$ \\
\hline $\begin{array}{l}1926.07- \\
1946.12\end{array}$ & $\begin{array}{c}0.0758 * \\
(0.0349)\end{array}$ & $\begin{array}{c}0.2869 \\
(0.1611)\end{array}$ & $\begin{array}{l}-0.0205 \\
(0.0293)\end{array}$ & $\begin{array}{c}0.2992 \\
(0.2011)\end{array}$ & $\begin{array}{l}-0.3787 * * \\
(0.0853)\end{array}$ \\
\hline $\begin{array}{l}1947.01- \\
1977.12\end{array}$ & $\begin{array}{l}0.0656^{* *} \\
(0.0148)\end{array}$ & $\begin{array}{l}0.1417^{* *} \\
(0.0511)\end{array}$ & $\begin{array}{l}0.0730 * * \\
(0.0130)\end{array}$ & $\begin{array}{c}0.1397 * \\
(0.0645)\end{array}$ & $\begin{array}{l}-0.2571 * * \\
(0.0984)\end{array}$ \\
\hline $\begin{array}{l}1978.01- \\
2003.07\end{array}$ & $\begin{array}{l}0.0711 * * \\
(0.0143)\end{array}$ & $\begin{array}{c}0.1298 * \\
(0.0541)\end{array}$ & $\begin{array}{l}0.0603 * * \\
(0.0124)\end{array}$ & $\begin{array}{c}0.1196^{*} \\
(0.0518)\end{array}$ & $\begin{array}{l}-0.0665 \\
(0.1204)\end{array}$ \\
\hline \multirow[t]{2}{*}{$\begin{array}{l}1947.01- \\
2003.07\end{array}$} & $\begin{array}{l}0.0681 * * \\
(0.0107)\end{array}$ & $\begin{array}{l}0.1364 * * \\
(0.0449)\end{array}$ & $\begin{array}{l}0.0672 * * \\
(0.0093)\end{array}$ & $\begin{array}{c}0.1310^{*} \\
(0.0512)\end{array}$ & $\begin{array}{l}-0.1828 * \\
(0.0798)\end{array}$ \\
\hline & & Panel B. & Contrarian Strategy & & \\
\hline $\begin{array}{l}1931.01- \\
2003.07\end{array}$ & $\begin{array}{l}0.0755^{* *} \\
(0.0131)\end{array}$ & $\begin{array}{c}0.1947 \\
(0.1083)\end{array}$ & $\begin{array}{l}-0.0333^{* *} \\
(0.0105)\end{array}$ & $\begin{array}{c}0.1567 \\
(0.0842)\end{array}$ & $\begin{array}{l}-0.2700 * * \\
(0.0472)\end{array}$ \\
\hline $\begin{array}{l}1931.01- \\
1946.12\end{array}$ & $\begin{array}{c}0.0892 * \\
(0.0445)\end{array}$ & $\begin{array}{c}0.3351 \\
(0.2171)\end{array}$ & $\begin{array}{l}-0.0817 * \\
(0.0325)\end{array}$ & $\begin{array}{c}0.2516 \\
(0.1615)\end{array}$ & $\begin{array}{l}-0.3279 * * \\
(0.0785)\end{array}$ \\
\hline $\begin{array}{l}1947.01- \\
1977.12\end{array}$ & $\begin{array}{l}0.0655^{* *} \\
(0.0141)\end{array}$ & $\begin{array}{l}0.1341^{* *} \\
(0.0484)\end{array}$ & $\begin{array}{l}-0.0244 \\
(0.0128)\end{array}$ & $\begin{array}{c}0.1258^{*} \\
(0.0578)\end{array}$ & $\begin{array}{l}-0.2148^{*} \\
(0.0897)\end{array}$ \\
\hline $\begin{array}{l}1978.01- \\
2003.07\end{array}$ & $\begin{array}{l}0.0790^{* *} \\
(0.0137)\end{array}$ & $\begin{array}{c}0.1251 * \\
(0.0524)\end{array}$ & $\begin{array}{l}-0.0139 \\
(0.0100)\end{array}$ & $\begin{array}{c}0.0956^{*} \\
(0.0440)\end{array}$ & $\begin{array}{l}-0.1092 \\
(0.1119)\end{array}$ \\
\hline $\begin{array}{l}1947.01- \\
2003.07\end{array}$ & $\begin{array}{l}0.0716^{* *} \\
(0.0102)\end{array}$ & $\begin{array}{l}0.1302 * * \\
(0.0432)\end{array}$ & $\begin{array}{c}-0.0197 * \\
(0.0088)\end{array}$ & $\begin{array}{c}0.1132 * \\
(0.0465)\end{array}$ & $\begin{array}{l}-0.1722 * \\
(0.0727)\end{array}$ \\
\hline
\end{tabular}


Table 3

\section{Momentum and Contrarian Profits and Return Persistence}

This table reports the average realized momentum/contrarian profits, their predicted counterparts based on the return persistence $\left(b_{t+h} \times r_{W M L, t-f}\right)$, the difference between the realized and the predicted profits, and the results of regressing the realized momentum/contrarian profits on the predicted counterpart, i.e., $\pi_{t+h}=c_{0}+c_{1} \times\left(b_{t+h} \times r_{W M L, t-f}\right)+e_{t+h}$, for the NYSE\&AMEX stocks. The WML portfolio is formed by the winner decile portfolio minus the loser decile portfolio based on the formation period returns (month $t-$ 6 through month $t-1$ for the momentum strategy in Panel A, and month $t-60$ to $t-55$ for the contrarian strategy in Panel B). $\pi_{t+h}$ denotes the six-month compounded WML returns for the holding period (month $t$ to $t+5) . \quad r_{W M L, t-f}$ denotes the compounded WML returns for the formation period. The columns labeled as "Means" report the averages of the time series. The standard errors are reported in parentheses. NeweyWest procedure is used to adjust the time-series persistence in these estimates. '*' indicates a $5 \%$ significance level and ' $* *$ ' indicates a $1 \%$ significance level.

\begin{tabular}{|c|c|c|c|c|c|c|}
\hline & \multicolumn{3}{|c|}{ Means } & \multicolumn{3}{|c|}{ Regression } \\
\hline & $\pi_{t+h}$ & $b_{t+h} \times r_{W M L, t-f}$ & $\begin{array}{c}\pi_{t+h}- \\
b_{t+h} \times r_{W M L, t-f}\end{array}$ & $c_{0}$ & $c_{1}$ & Adj. $\mathrm{R}^{2}$ \\
\hline & & Panel A. & \multicolumn{2}{|c|}{ Momentum Strategy } & & \\
\hline $1926.07-2003.07$ & $\begin{array}{c}0.0240^{*} \\
(0.0118)\end{array}$ & $\begin{array}{l}0.0329 * * \\
(0.0096)\end{array}$ & $\begin{array}{l}-0.0089^{*} \\
(0.0035)\end{array}$ & $\begin{array}{l}-0.0139^{* *} \\
(0.0035)\end{array}$ & $\begin{array}{l}1.1538^{* *} \\
(0.0273)\end{array}$ & 0.9104 \\
\hline $1926.07-1946.12$ & $\begin{array}{c}-0.0552 \\
(0.0331)\end{array}$ & $\begin{array}{l}-0.0198 \\
(0.0265)\end{array}$ & $\begin{array}{l}-0.0354 * * \\
(0.0089)\end{array}$ & $\begin{array}{l}-0.0318^{* *} \\
(0.0067)\end{array}$ & $\begin{array}{l}1.1813^{* *} \\
(0.0283)\end{array}$ & 0.9256 \\
\hline $1947.01-1977.12$ & $\begin{array}{l}0.0484 * * \\
(0.0102)\end{array}$ & $\begin{array}{l}0.0479^{* *} \\
(0.0097)\end{array}$ & $\begin{array}{c}0.0006 \\
(0.0025)\end{array}$ & $\begin{array}{l}-0.0001 \\
(0.0029)\end{array}$ & $\begin{array}{l}1.0142 * * \\
(0.0299)\end{array}$ & 0.9231 \\
\hline $1978.01-2003.07$ & $\begin{array}{l}0.0579 * * \\
(0.0141)\end{array}$ & $\begin{array}{l}0.0569 * * \\
(0.0116)\end{array}$ & $\begin{array}{c}0.0009 \\
(0.0055)\end{array}$ & $\begin{array}{c}-0.0046 \\
(0.0084)\end{array}$ & $\begin{array}{l}1.0966^{* *} \\
(0.0716)\end{array}$ & 0.8370 \\
\hline $1947.01-2003.07$ & $\begin{array}{l}0.0527 * * \\
(0.0087)\end{array}$ & $\begin{array}{l}0.0520^{* *} \\
(0.0076)\end{array}$ & $\begin{array}{c}0.0007 \\
(0.0029)\end{array}$ & $\begin{array}{c}-0.0021 \\
(0.0043)\end{array}$ & $\begin{array}{l}1.0554 * * \\
(0.0410)\end{array}$ & 0.8737 \\
\hline & & Panel B. & Contrarian & ategy & & \\
\hline 1931.01-2003.07 & $\begin{array}{l}-0.0232 * * \\
(0.0077)\end{array}$ & $\begin{array}{l}-0.0227 * * \\
(0.0073)\end{array}$ & $\begin{array}{l}-0.0005 \\
(0.0023)\end{array}$ & $\begin{array}{l}-0.0002 \\
(0.0019\end{array}$ & $\begin{array}{l}1.0147 * * \\
(0.0292)\end{array}$ & 0.8808 \\
\hline $1931.01-1946.12$ & $\begin{array}{c}-0.0621 * \\
(0.0248)\end{array}$ & $\begin{array}{c}-0.0528 * \\
(0.0224)\end{array}$ & $\begin{array}{c}-0.0092 \\
(0.0079)\end{array}$ & $\begin{array}{c}-0.0072 \\
(0.0062)\end{array}$ & $\begin{array}{l}1.0374 * * \\
(0.0433)\end{array}$ & 0.8729 \\
\hline $1947.01-1977.12$ & $\begin{array}{c}-0.0156^{*} \\
(0.0078)\end{array}$ & $\begin{array}{c}-0.0161 * \\
(0.0079)\end{array}$ & $\begin{array}{c}0.0005 \\
(0.0018)\end{array}$ & $\begin{array}{l}-0.0001 \\
(0.0017)\end{array}$ & $\begin{array}{l}0.9603 * * \\
(0.0231)\end{array}$ & 0.9143 \\
\hline $1978.01-2003.07$ & $\begin{array}{l}-0.0081 \\
(0.0091)\end{array}$ & $\begin{array}{c}-0.0118 \\
(0.0089)\end{array}$ & $\begin{array}{c}0.0037 \\
(0.0028)\end{array}$ & $\begin{array}{c}0.0035 \\
(0.0028)\end{array}$ & $\begin{array}{l}0.9830 * * \\
(0.0299)\end{array}$ & 0.8628 \\
\hline $1947.01-2003.07$ & $\begin{array}{c}-0.0122 * \\
(0.0062)\end{array}$ & $\begin{array}{c}-0.0142 * \\
(0.0063)\end{array}$ & $\begin{array}{c}0.0019 \\
(0.0017)\end{array}$ & $\begin{array}{c}0.0015 \\
(0.0016)\end{array}$ & $\begin{array}{l}0.9715^{* *} \\
(0.0199)\end{array}$ & 0.8887 \\
\hline
\end{tabular}


Table 4

\section{Decomposition of the Market Return}

This table reports the average realized market returns, the persistence component of the market return $\left(b_{t+h} \times r_{m, t-f}\right)$, the difference between the realized and the predicted market returns $\left(\Delta r_{m, t+h}=r_{m, t+h}-a_{t+h}-b_{t+h} \times r_{m, t-f}\right)$, and the results of regressing the realized market return $r_{m, t+h}$ (compounded from month $t$ to $t+5)$ on the non-persistence component $\left(a_{t+h}\right)$ and the persistence component of the market return, i.e.,

$$
r_{m, t+h}=c_{0}+c_{1} \times a_{t+h}+c_{2} \times\left(b_{t+h} \times r_{m, t-f}\right)+e_{t+h}
$$

where $r_{m, t-f}$ denotes the compounded market returns in the formation period (month $t-6$ to $t-1$ for the momentum strategy in Panel A, and month $t-60$ to $t-55$ for the contrarian strategy in Panel B). The market return refers to the equally weighted returns of all stocks traded on the NYSE and AMEX. The columns under "Summary Statistics" report the average of the respective time series as well the correlation between $a_{t+h}$ and $r_{m, t-f}$ (Correl). The standard errors are reported in parentheses. Newey-West procedure is used to adjust the time-series persistence in these estimates. ' $*$ ' indicates a $5 \%$ significance level and '**' indicates a $1 \%$ significance level.

\begin{tabular}{|c|c|c|c|c|c|c|c|c|}
\hline & \multicolumn{4}{|c|}{ Summary Statistics } & \multicolumn{4}{|c|}{ Regression } \\
\hline & $r_{m, t+h}$ & $b_{t+h} \times r_{m, t-f}$ & $\Delta r_{m, t+h}$ & Correl & $c_{0}$ & $c_{1}$ & $c_{2}$ & Adj. $\mathrm{R}^{2}$ \\
\hline & & & Panel A. & \multicolumn{2}{|c|}{ Momentum Strategy } & & & \\
\hline $\begin{array}{l}1926.07- \\
2003.07\end{array}$ & $\begin{array}{c}0.0829 * * \\
(0.0147)\end{array}$ & $\begin{array}{c}0.0070 * * \\
(0.0023)\end{array}$ & $\begin{array}{c}0.0058 * * \\
(0.0017)\end{array}$ & $\begin{array}{c}0.0477 \\
(0.0522)\end{array}$ & $\begin{array}{c}0.0026 \\
(0.0015)\end{array}$ & $\begin{array}{c}1.0296 * * \\
(0.0252)\end{array}$ & $\begin{array}{l}1.1548 * * \\
(0.0723)\end{array}$ & 0.9911 \\
\hline $\begin{array}{l}1926.07- \\
1946.12\end{array}$ & $\begin{array}{l}0.1038^{*} \\
(0.0417)\end{array}$ & $\begin{array}{c}0.0117 \\
(0.0076)\end{array}$ & $\begin{array}{l}0.0162 * * \\
(0.0051)\end{array}$ & $\begin{array}{c}0.1267 \\
(0.0691)\end{array}$ & $\begin{array}{c}0.0110 * * \\
(0.0036)\end{array}$ & $\begin{array}{l}1.0442 * * \\
(0.0329)\end{array}$ & $\begin{array}{l}1.1590 * * \\
(0.0785)\end{array}$ & 0.9903 \\
\hline $\begin{array}{l}1947.01- \\
1977.12\end{array}$ & $\begin{array}{c}0.0718 * * \\
(0.0163)\end{array}$ & $\begin{array}{l}0.0048^{*} \\
(0.0022)\end{array}$ & $\begin{array}{c}0.0014 \\
(0.0010)\end{array}$ & $\begin{array}{c}-0.0557 \\
(0.0938)\end{array}$ & $\begin{array}{c}0.0004 \\
(0.0007)\end{array}$ & $\begin{array}{l}1.0122 * * \\
(0.0072)\end{array}$ & $\begin{array}{l}1.0281 * * \\
(0.0447)\end{array}$ & 0.9963 \\
\hline $\begin{array}{l}1978.01- \\
2003.07\end{array}$ & $\begin{array}{c}0.0791 * * \\
(0.0148)\end{array}$ & $\begin{array}{c}0.0058 * * \\
(0.0015)\end{array}$ & $\begin{array}{l}0.0028 * * \\
(0.0009)\end{array}$ & $\begin{array}{l}-0.1635 \\
(0.0991)\end{array}$ & $\begin{array}{l}0.0023 * \\
(0.0010)\end{array}$ & $\begin{array}{l}1.0068 * * \\
(0.0050)\end{array}$ & $\begin{array}{l}1.0094 * * \\
(0.0738)\end{array}$ & 0.9950 \\
\hline \multirow[t]{2}{*}{$\begin{array}{l}1947.01- \\
2003.07\end{array}$} & $\begin{array}{c}0.0751 * * \\
(0.0115)\end{array}$ & $\begin{array}{c}0.0052 * * \\
(0.0014)\end{array}$ & $\begin{array}{l}0.0020 * * \\
(0.0007)\end{array}$ & $\begin{array}{l}-0.0975 \\
(0.0706)\end{array}$ & $\begin{array}{l}0.0012 * \\
(0.0006)\end{array}$ & $\begin{array}{c}1.0101 * * \\
(0.0047)\end{array}$ & $\begin{array}{l}1.0264 * * \\
(0.0379)\end{array}$ & 0.9958 \\
\hline & & & Panel B. & Contraria & Strategy & & & \\
\hline $\begin{array}{l}1931.01- \\
2003.07\end{array}$ & $\begin{array}{c}0.0876 * * \\
(0.0150)\end{array}$ & $\begin{array}{l}0.0063 * \\
(0.0025)\end{array}$ & $\begin{array}{l}0.0058 * * \\
(0.0020)\end{array}$ & $\begin{array}{c}-0.0411 \\
(0.0493)\end{array}$ & $\begin{array}{c}0.0012 \\
(0.0018)\end{array}$ & $\begin{array}{l}1.0632 * * \\
(0.0191)\end{array}$ & $\begin{array}{c}0.9736 * * \\
(0.0345)\end{array}$ & 0.9884 \\
\hline $\begin{array}{l}1931.01- \\
1946.12\end{array}$ & $\begin{array}{c}0.1308 * * \\
(0.0504)\end{array}$ & $\begin{array}{l}0.0204 * \\
(0.0092)\end{array}$ & $\begin{array}{l}0.0212 * * \\
(0.0052)\end{array}$ & $\begin{array}{c}-0.0850 \\
(0.0889)\end{array}$ & $\begin{array}{c}0.0173 * * \\
(0.0038)\end{array}$ & $\begin{array}{l}1.0707 * * \\
(0.0182)\end{array}$ & $\begin{array}{c}0.8814 * * \\
(0.0322)\end{array}$ & 0.9939 \\
\hline $\begin{array}{l}1947.01- \\
1977.12\end{array}$ & $\begin{array}{c}0.0718 * * \\
(0.0163)\end{array}$ & $\begin{array}{c}0.0028 \\
(0.0021)\end{array}$ & $\begin{array}{c}0.0035 \\
(0.0027)\end{array}$ & $\begin{array}{c}0.1053 \\
(0.1033)\end{array}$ & $\begin{array}{l}-0.0015 \\
(0.0019)\end{array}$ & $\begin{array}{c}1.0686 * * \\
(0.0152)\end{array}$ & $\begin{array}{l}1.1522 * * \\
(0.1485)\end{array}$ & 0.9793 \\
\hline $\begin{array}{l}1978.01- \\
2003.07\end{array}$ & $\begin{array}{c}0.0791 * * \\
(0.0148)\end{array}$ & $\begin{array}{c}0.0018 \\
(0.0014)\end{array}$ & $\begin{array}{l}-0.0011 \\
(0.0014)\end{array}$ & $\begin{array}{c}-0.1094 \\
(0.0917)\end{array}$ & $\begin{array}{l}-0.0020 \\
(0.0015)\end{array}$ & $\begin{array}{c}1.0083 * * \\
(0.0081)\end{array}$ & $\begin{array}{l}1.1059 * * \\
(0.0878)\end{array}$ & 0.9912 \\
\hline $\begin{array}{l}1947.01- \\
2003.07 \\
\end{array}$ & $\begin{array}{c}0.0751 * * \\
(0.0115) \\
\end{array}$ & $\begin{array}{c}0.0023 \\
(0.0014)\end{array}$ & $\begin{array}{c}0.0014 \\
(0.0017)\end{array}$ & $\begin{array}{c}0.0124 \\
(0.0730)\end{array}$ & $\begin{array}{c}-0.0019 \\
(0.0013)\end{array}$ & $\begin{array}{c}1.0417 * * \\
(0.0109)\end{array}$ & $\begin{array}{c}1.1483 * * \\
(0.1200)\end{array}$ & 0.9829 \\
\hline
\end{tabular}




\section{Table 5}

\section{The Conditional Test under the CRRA Model}

This table presents the results of the GMM tests of the three restrictions on the stochastic discount factor under the CRRA model. Restriction (I) indicates the rationality of WML returns, restriction (II) indicates the rationality of the market returns, and restriction (III) indicates a relation between the return persistence and the intertemporal dependence structure in the stochastic discount factor. For columns under "Momentum", we test the restrictions underlying the momentum profit with holding period covering two quarters from month $t$ to $t+5$ and formation period covering month $t$ - 6 through $t-1$. For columns under "Contrarian", we test the restrictions underlying the contrarian profit with holding period covering two quarters from month $t$ to $t+5$ and formation period covering month $t$ - 60 through $t-55$. For columns under "Momentum \& Contrarian", we test the restrictions underlying both the momentum and the contrarian profits. Instruments used including (1) the unity vector; (2) the equally weighted CRSP market index return $r_{m, t} ;(3)$ the economy-wide default spread $d e f_{t}$; (4) the CRSP dividend yield $d i v_{t}$; (5) the term structure spread term $_{t}$; and (6) the short term bond yield $y l d_{t}$. For the market index return, we use observations for the two quarters that cover month $t-6$ to month $t-1$. For the other four variables, we use observations for the month of $t-1$. The standard errors are reported in parentheses. Newey-West procedure is used to adjust the time-series persistence in these estimates. The $J$-statistic tests the over-identification restrictions. The pvalue of the $J$-test is reported in brackets. ' $*$ ' indicates a $5 \%$ significance level and '**' indicates a $1 \%$ significance level. The sample period is from 1952Q4-2003Q3 for the momentum strategy and from 1957Q2 to 2003Q3 for the contrarian strategy.

\begin{tabular}{cccc}
\hline & Momentum & Contrarian & Momentum \& Contrarian \\
\hline \multirow{2}{*}{$\beta$} & $1.0074^{* *}$ & $0.9894^{* * *}$ & $0.9983^{* *}$ \\
& $(0.0081)$ & $(0.0122)$ & $(0.0061)$ \\
$\gamma$ & $6.8886^{* *}$ & $5.2493^{* *}$ & $6.1713^{* *}$ \\
\multirow{2}{*}{$J$-test } & $(0.3127)$ & $(0.6045)$ & $(0.2392)$ \\
& 24.0804 & 15.2202 & 30.7504 \\
& {$[0.0877]$} & {$[0.3536]$} & {$[0.6277]$} \\
\hline
\end{tabular}


Table 6

The Conditional Test under the Epstein-Zin Recursive Preference Model

This table presents the results of the GMM tests of the three restrictions on the stochastic discount factor under the Epstein-Zin recursive preference model. Restriction (I) indicates the rationality of WML returns, restriction (II) indicates the rationality of the market returns, and restriction (III) indicates a relation between the return persistence and the intertemporal dependence structure in the stochastic discount factor. For columns under "Momentum", we test the restrictions underlying the momentum profit with holding period covering two quarters from month $t$ to $t+5$ and formation period covering month $t$ - 6 through $t-1$. For columns under "Contrarian", we test the restrictions underlying the contrarian profit with holding period covering two quarters from month $t$ to $t+5$ and formation period covering month $t-60$ through $t-55$. For columns under "Momentum \& Contrarian", we test the restrictions underlying both the momentum and the contrarian profits. Instruments used including (1) the unity vector; (2) the equally weighted CRSP market index return $r_{m, t} ;(3)$ the economy-wide default spread $d e f_{t}$; (4) the CRSP dividend yield $d i v_{t}$; (5) the term structure spread term $_{t}$; and (6) the short term bond yield $y l d_{t}$. For the market index return, we use observations for the two quarters that cover month $t-6$ to month $t-1$. For the other four variables, we use observations for the month of $t-1$. The standard errors are reported in parentheses. Newey-West procedure is used to adjust the time-series persistence in these estimates. The $J$-statistic tests the over-identification restrictions. The p-value of the $J$-test is reported in brackets. ' $*$ ' indicates a $5 \%$ significance level and '**' indicates a 1\% significance level. The sample period is from 1952Q4-2003Q3 for the momentum strategy and from 1957Q2 to 2003Q3 for the contrarian strategy.

\begin{tabular}{cccc}
\hline Momentum & Contrarian & $\begin{array}{c}\text { Momentum \& } \\
\text { Contrarian }\end{array}$ \\
\hline$\beta$ & $1.1747^{* *}$ & $1.0901^{* *}$ & $1.1535^{* *}$ \\
$\gamma$ & $(0.1053)$ & $(0.0971)$ & $(0.0385)$ \\
$\psi$ & $3.5228^{* *}$ & $1.8040^{*}$ & $2.8617^{* *}$ \\
& $(0.8148)$ & $(0.8019)$ & $(0.1950)$ \\
$J$-test & $0.0698^{*}$ & 0.1502 & $0.0808^{* *}$ \\
& $(0.0322)$ & $(0.1431)$ & $(0.0139)$ \\
& 18.9454 & 9.9599 & 23.2155 \\
& {$[0.2162]$} & {$[0.8223]$} & {$[0.8971]$} \\
\hline
\end{tabular}


Table 7

The Conditional Test of under the External Habit Formation Model

The table presents the results of the GMM tests of the three restrictions on the stochastic discount factor under the external habit formation model. Restriction (I) indicates the rationality of WML returns, restriction (II) indicates the rationality of the market returns, and restriction (III) indicates a relation between the return persistence and the intertemporal dependence structure in the stochastic discount factor. For columns under "Momentum", we test the restrictions underlying the momentum profit with holding period covering two quarters from month $t$ to $t+5$ and formation period covering month $t$ - 6 through $t$ - 1 . For columns under "Contrarian", we test the restrictions underlying the contrarian profit with holding period covering two quarters from month $t$ to $t+5$ and formation period covering month $t$-60 through $t-55$. For columns under "Momentum \& Contrarian", we test the restrictions underlying both the momentum and the contrarian returns. Instruments used including (1) the unity vector; (2) the equally weighted CRSP market index return $r_{m, t}$; (3) the economy-wide default spread $d e f_{t}$; (4) the CRSP dividend yield $d i v_{t}$; (5) the term structure spread term $_{t}$; and (6) the short term bond yield $y l d_{t}$. For the market index return, we use observations for the two quarters that cover month $t-6$ to month $t-1$. For the other four variables, we use observations for the month of $t-1$. The standard errors are reported in parentheses. Newey-West procedure is used to adjust the time-series persistence in these estimates. The $J$-statistic tests the over-identification restrictions. The p-value of the $J$-test is reported in brackets. ' $*$ ' indicates a $5 \%$ significance level and ' $* *$ ' indicates a 1\% significance level. The sample period is from 1952Q4-2003Q3 for the momentum strategy and from 1957Q2 to 2003Q3 for the contrarian strategy.

\begin{tabular}{cccc}
\hline Momentum & Contrarian & $\begin{array}{c}\text { Momentum \& } \\
\text { Contrarian }\end{array}$ \\
\hline$\beta$ & $0.9115^{* *}$ & $0.7206^{* *}$ & $0.8552^{* *}$ \\
$\gamma$ & $(0.1516)$ & $(0.1245)$ & $(0.2125)$ \\
$\phi$ & 4.2390 & $5.9059^{* *}$ & 5.5290 \\
& $(3.0679)$ & $(1.8441)$ & $(4.3568)$ \\
& $0.8488^{* *}$ & $0.8759^{* *}$ & $0.8408^{* *}$ \\
& $(0.1213)$ & $(0.0954)$ & $(0.1456)$ \\
& 24.4211 & 13.3190 & 30.3746 \\
& {$[0.0583]$} & {$[0.5777]$} & {$[0.5985]$} \\
\hline
\end{tabular}


Table 8

Regression Analysis under the CRRA and Epstein-Zin Preference Models

The table presents the results of the regression analysis on the per capita consumption growth rate $\left(g_{t+h}\right)$ of the holding period (compounded for the two quarters that cover month $t$ through $t+5$ ) on the formation period consumption growth rate for the short-term intertemporal dependence under momentum strategy (Panel A) and the long-term intertemporal dependence under contrarian strategy (Panel B) using specification (17),

$$
g_{t+h}=c_{0}+c_{1} \times a_{t+h}+c_{2} \times\left(1-b_{t+h}\right)+c_{3} \times\left(b_{t+h} \times g_{t-f}\right)+e_{t+h}
$$

where $g_{t-f}$ denotes the compounded per capita consumption growth rate for the two quarters that cover month $t-6$ through $t$ - 1 , for the momentum strategy, and for the two quarters covering month $t$ - 60 through $t$ 55 for the contrarian strategy. The $F$-test tests the joint hypotheses $c_{1}=0$ and $c_{3}=0$. The standard errors are reported in parentheses. Newey-West procedure is used to adjust the time-series persistence in these estimates. The p-value of the $F$-test is reported in brackets. '*' indicates a $5 \%$ significance level and '**' indicates a $1 \%$ significance level.

\begin{tabular}{llllll}
\hline$c_{0}$ & $c_{1}$ & $c_{2}$ & $c_{3}$ & Adj. R & $\begin{array}{c}F \text {-test } \\
\left(c_{1}=0 \text { and } c_{3}=0\right)\end{array}$ \\
\hline
\end{tabular}

Panel A. Momentum Strategy

$\begin{array}{lcccccc}\text { 1952Q4- } & 0.0036 & 0.0111^{* *} & 0.0059 & 1.1701 * * & 0.0750 & 9.9468^{* *} \\ \text { 2003Q3 } & (0.0062) & (0.0037) & (0.0065) & (0.4348) & & {[0.0001]} \\ \text { 1952Q4- } & 0.0039 & 0.0139 * * & 0.0067 & 0.9414 * & 0.0832 & 6.9656^{* *} \\ \text { 1977Q4 } & (0.0074) & (0.0051) & (0.0076) & (0.4439) & & {[0.0015]} \\ \text { 1978Q1- } & 0.0071 & 0.0071 & 0.0012 & 1.2171 & 0.0539 & 2.6440 \\ \text { 2003Q3 } & (0.0098) & (0.0056) & (0.0103) & (0.6558) & & {[0.0761]}\end{array}$

Panel B. Contrarian Strategy

$\begin{array}{lcccccc}\text { 1957Q2- } & -0.0065 & 0.0070 & 0.0166^{*} & 0.8996 & 0.0546 & 3.4178^{*} \\ \text { 2003Q3 } & (0.0066) & (0.0038) & (0.0066) & (0.5807) & & {[0.0328]} \\ \text { 1957Q2- } & 0.0018 & 0.0112 * & 0.0098 & 0.4797 & 0.0556 & 2.3609 \\ \text { 1977Q4 } & (0.0089) & (0.0057) & (0.0087) & (0.7101) & & {[0.1010]} \\ \text { 1978Q1- } & -0.0167 & 0.0038 & 0.0258^{*} & 2.1792 * & 0.0369 & 2.6975 \\ \text { 2003Q3 } & (0.0115) & (0.0051) & (0.0115) & (1.1086) & & {[0.0723]}\end{array}$




\section{Table 9}

\section{Regression Analysis under the External Habit Formation Model}

This table presents the results of the regression analysis of the per capita surplus consumption growth rate $g c s_{t+h}$ of the holding period (compounded for the two quarters that cover month $t$ through $t+5$ ) on the formation period surplus consumption growth rate for the short-term intertemporal dependence under momentum strategy (Panel A) and the long-term intertemporal dependence under contrarian strategy (Panel B) using specification (19),

$$
g c s_{t+h}=c_{0}+c_{1} \times a_{t+h}+c_{2} \times\left(1-b_{t+h}\right)+c_{3} \times\left(b_{t+h} \times g c s_{t-f}\right)+e_{t+h}
$$

where $g c s_{t-f}$ denotes the compounded per capita surplus consumption growth rate for the two quarters that cover month $t-6$ through $t-1$ for the momentum strategy, and for the two quarters covering month $t-60$ through $t-55$ for the contrarian strategy. The habit persistence parameter is estimated as in the last column of Table 7. The $F$-test tests the joint hypotheses $c_{1}=0$ and $c_{3}=0$. The standard errors are reported in parentheses. Newey-West procedure is used to adjust the time-series persistence in these estimates. The pvalue of the $F$-test is reported in brackets. ' $*$ ' indicates a $5 \%$ significance level and ' $* *$ ' indicates a $1 \%$ significance level.

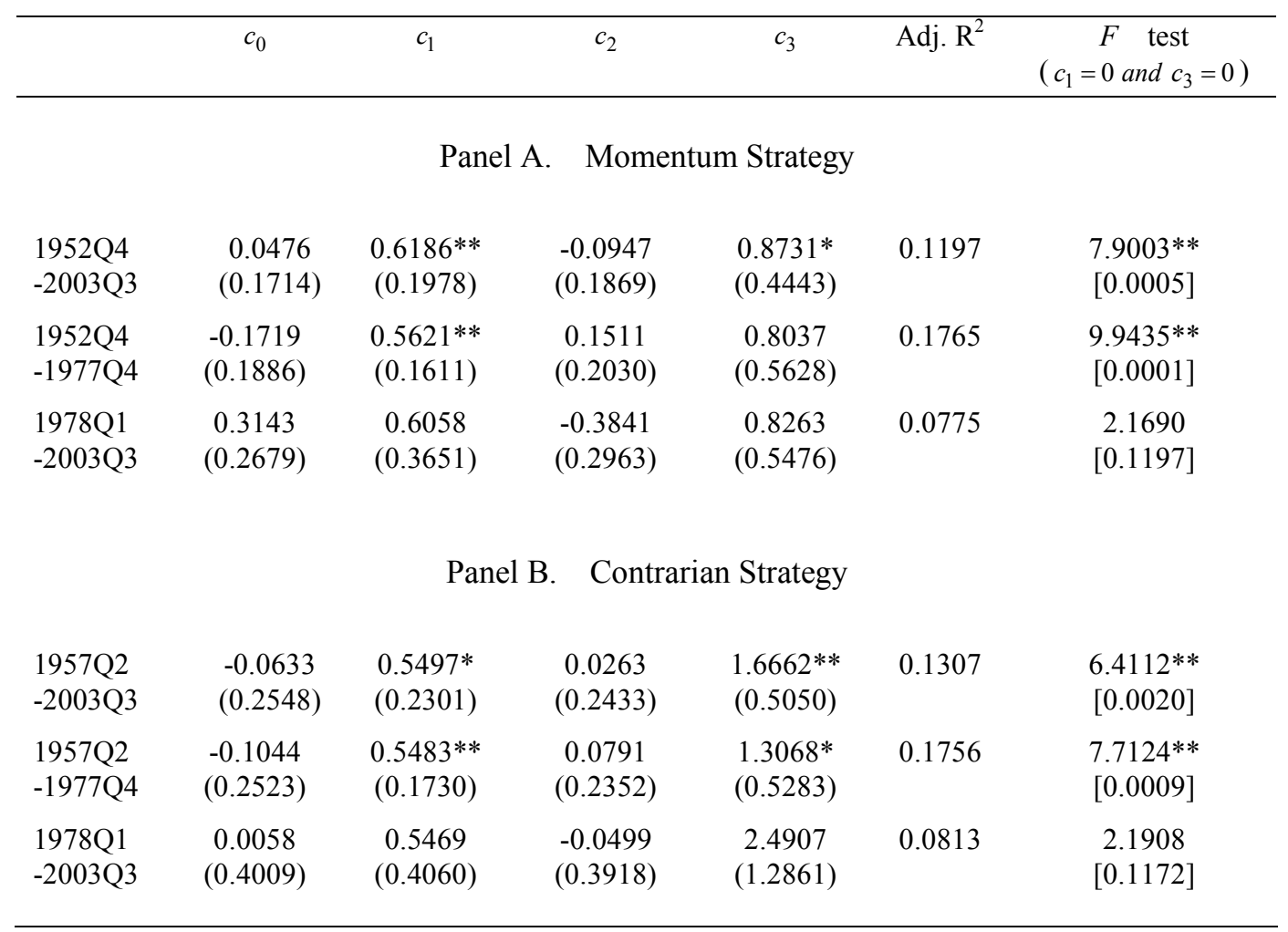


Figure 1

This figure illustrates the time-series of the momentum profit (Panel A) and the contrarian profit (Panel B) in the six-month holding period (month $t$ to $t+5$, solid line) and their predicted counterparts (dashed line) $b_{t+h} \times r_{W M L, t-f}$. The sample period is from July 1926 to July 2003 for the momentum profit and from January 1931 to July 2003 for the contrarian profit. The return persistence parameter $b_{t+h}$ is estimated using NYSE and AMEX monthly stock return data.

Panel A. Momentum Profit

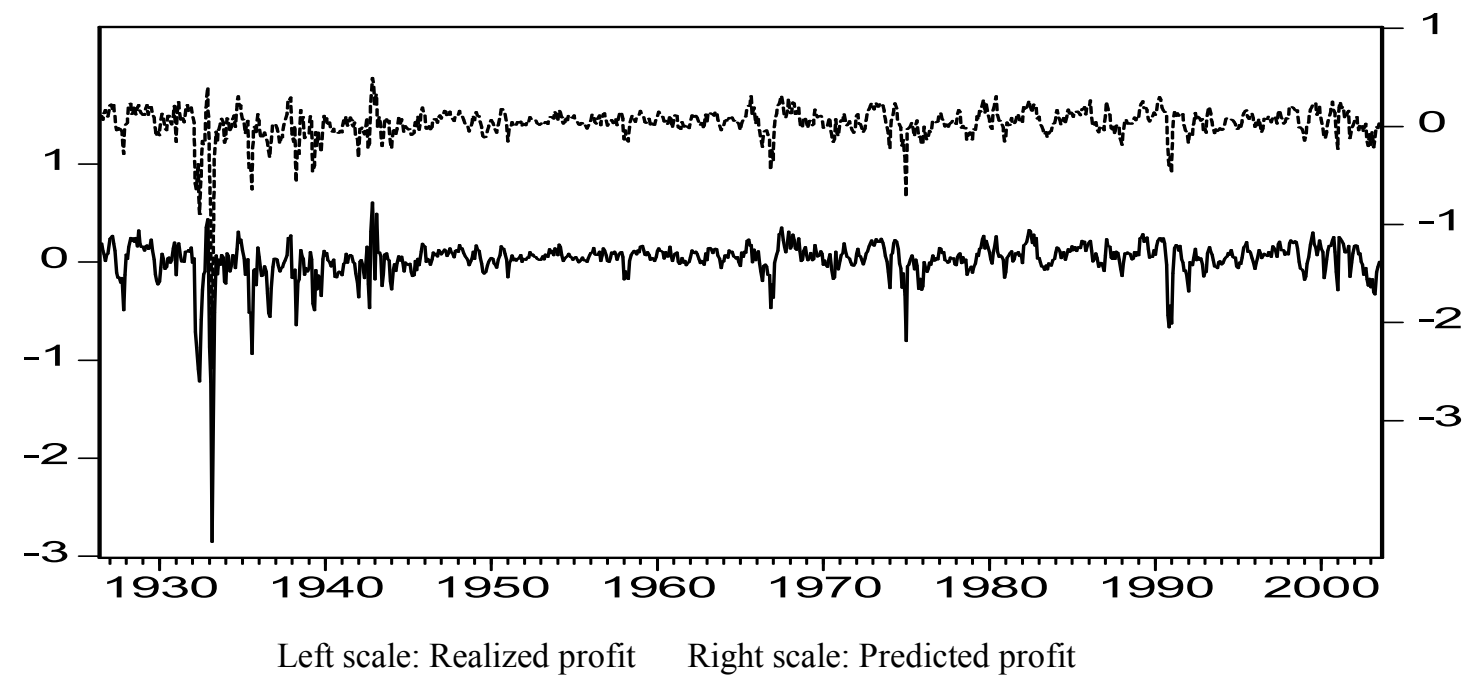

Panel B. Contrarian Profit

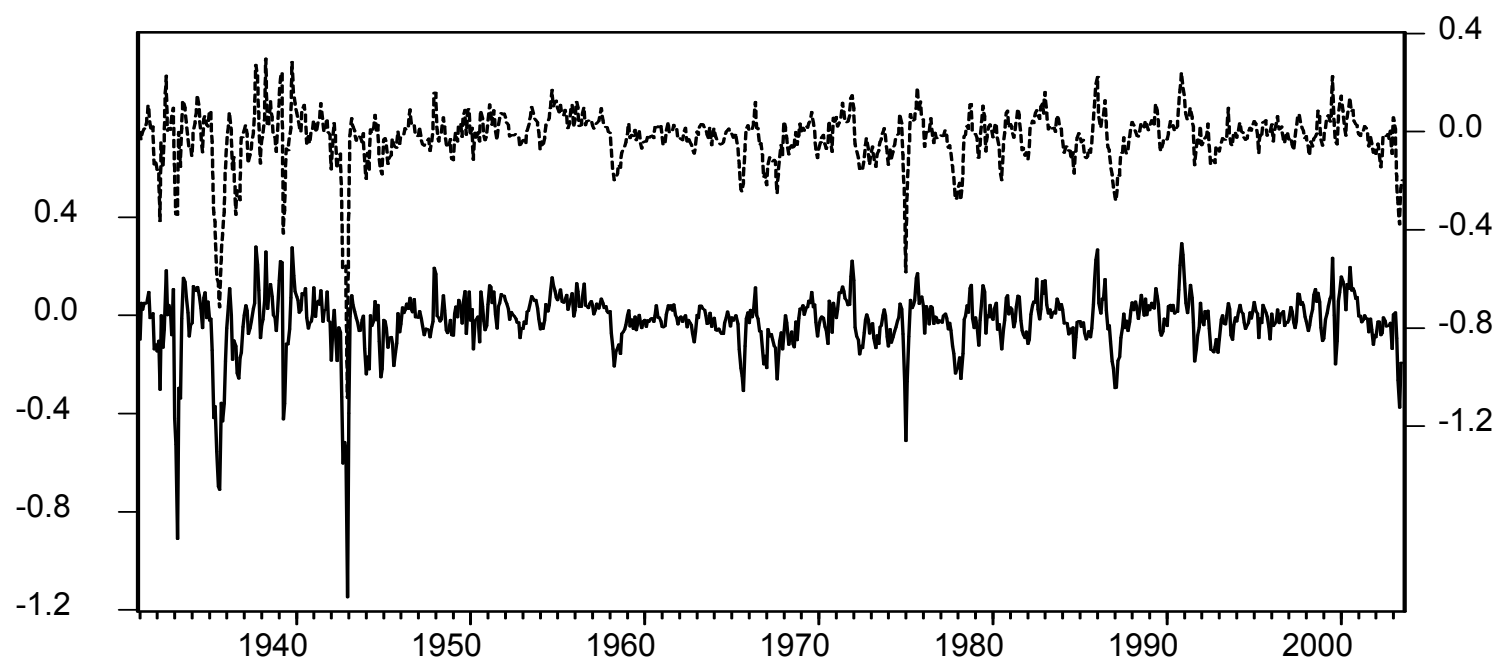

Left scale: Realized profit Right scale: Predicted profit 